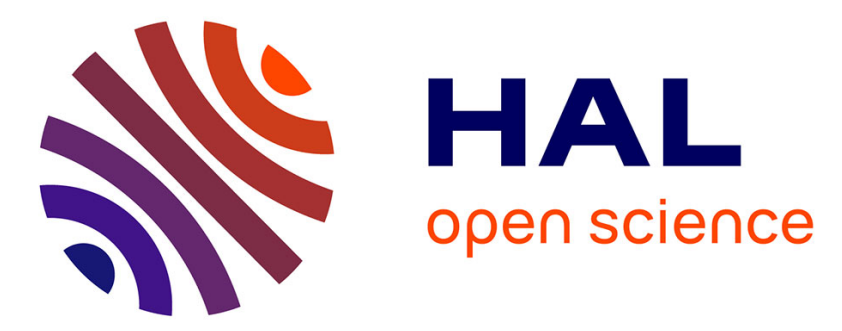

\title{
Updated recommendations of the International Society of Geriatric Oncology on prostate cancer management in older patients
}

H.J. Boyle, S. Alibhai, L. Decoster, E. Efstathiou, K. Fizazi, N. Mottet, S. Oudard, H. Payne, M. Prentice, M. Puts, et al.

\section{To cite this version:}

H.J. Boyle, S. Alibhai, L. Decoster, E. Efstathiou, K. Fizazi, et al.. Updated recommendations of the International Society of Geriatric Oncology on prostate cancer management in older patients. European Journal of Cancer, 2019, 116, pp.116 - 136. 10.1016/j.ejca.2019.04.031 • hal-03480703

\section{HAL Id: hal-03480703 https://hal.science/hal-03480703}

Submitted on 20 Dec 2021

HAL is a multi-disciplinary open access archive for the deposit and dissemination of scientific research documents, whether they are published or not. The documents may come from teaching and research institutions in France or abroad, or from public or private research centers.
L'archive ouverte pluridisciplinaire HAL, est destinée au dépôt et à la diffusion de documents scientifiques de niveau recherche, publiés ou non, émanant des établissements d'enseignement et de recherche français ou étrangers, des laboratoires publics ou privés.

\section{(c) (1) $\$$}

Distributed under a Creative Commons Attribution - NonCommerciall 4.0 International 


\section{Article type: REVIEW}

Title: Updated recommendations of the International Society of Geriatric Oncology (SIOG) on prostate cancer management in older patients

Authors: H J Boyle, S Alibhai, L Decoster, E Efstathiou, K Fizazi, N Mottet, S Oudard, H Payne, M Prentice, M Puts, M Aapro, J-P Droz

\section{Affiliations}

- HJ Boyle, MD: Department of Medical Oncology, Centre Léon-Bérard, Lyon, France

- $\quad$ S Alibhai , MD, MSc: Oncology Program, Princess Margaret Cancer Centre, University Health Network, Toronto, Canada

- $\quad$ L Decoster MD: Department of Medical Oncology, UZ Brussel, Vrije Universiteit Brussel, Brussels, Belgium

- E Efstathiou MD, PhD : Department of Genitourinary Medical Oncology, University of Texas, MD Anderson Cancer Center, Houston ,USA.

- $\quad$ K Fizazi, MD, PhD: Department of Genitourinary Medical Oncology, Gustave-Roussy, University of Paris-Sud, Villejuif, France

- $\quad$ N Mottet MD, PhD: Urology department, University Hospital, Saint-Etienne, France

- $\quad$ S Oudard MD, PhD: Department of Oncology, Georges Pompidou Hospital, , Paris, France

- $\quad$ H Payne FRCR, M Prentice, MD: Department of Uro-Oncology, University College London Hospitals, London, UK

- $\quad$ M Puts, RN, PhD: Lawrence S. Bloomberg Faculty of Nursing, University of Toronto, Toronto, Canada

- $\quad$ M Aapro MD: Multidisplinary Oncology Institute, Clinique de Genolier, Genolier, Switzerland

- J-P Droz MD, PhD : Claude-Bernard-Lyon-1 University and Department of Medical Oncology,

Centre Léon-Bérard, Lyon, France

\section{Correspondance to:}

Dr Helen J Boyle :

Medical Oncology department.

Centre Léon-Bérard

28 rue Laënnec

69373 Lyon Cedex 08

France 
Mail : helen.boyle@lyon.unicancer.fr

Phone: +33426556752

\section{Abstract (299 words)}

Background: The median age of prostate cancer diagnosis is 66 years, and the median age of men who die of the disease is eighty. The public health impact of prostate cancer is already substantial and, given the rapidly aging world population, can only increase. In this context, International Society of Geriatric Oncology (SIOG) Task Forces have since 2010 been developing guidelines for the management of senior adults with prostate cancer.

Material and methods: Since prostate cancer and geriatric oncology are both rapidly evolving fields, a new multidisciplinary Task Force was formed in 2018 to update SIOG recommendations, principally on health status screening tools and treatment The task force reviewed pertinent articles published between June 2016 and June 2018 and abstracts from EAU,ESMO,ASCO and ASCO GU meetings over the same period, using search terms relevant to prostate cancer, the elderly, geriatric evaluation, local treatments, and advanced disease. Each member of the group proposed modifications to the previous guidelines. These were collated and circulated. The final manuscript reflects the expert consensus.

Results: The 2019 consensus is that men aged 75 and older with prostate cancer should be managed according to their individual health status, and not according to age. Based on available rapid health screening tools, geriatric evaluation and geriatric interventions, the Task Force recommends that patients are classified according to health status into three groups: 1) "healthy" or "fit" patients should have the same treatment options as younger patients; 2 ) "vulnerable" patients are candidates for geriatric interventions which - if successful -- may make it appropriate for them to receive standard treatment; and 3) "frail" patients with major impairments who should receive adapted or palliative treatment.

The 2019 SIOG Task Force recommendations also discuss prospects and unmet needs for health status evaluation in everyday practice in older patients with prostate cancer.

Key words: prostate cancer; older patients; literature update; treatment; geriatric evaluation

\section{Key messages:}

Individual health status, and not age should guide management of prostate cancer in older men ( $\geq 75)$. "Fit" patients should be given the same options as younger patients; "vulnerable" patients are candidates for geriatric interventions which may make it appropriate for them to receive standard treatment; "frail" patients with major impairments should receive adapted or palliative treatment. 


\section{7 words}

\section{Introduction}

Prostate cancer is the fourth most frequent cancer worldwide[1]. In more developed regions, the age standardized incidence per 100,000 is 68 and the age standardized mortality is 10 per 100,000[2]. Sixty percent of patients are aged 65 and older at diagnosis. This proportion will increase to $70 \%$ by 2040. Moreover, the total number of prostate cancer patients aged 70 and older will increase between 2018 and 2030 from 585,000 to 778,000[3]. Over the same period, prostate cancer deaths in men aged 70 and over are expected to almost double while the overall mortality rate is anticipated to be stable[1]. Although the median age at prostate cancer diagnosis is 66 years, the median age of men who develop metastatic disease is considerably older, and the median age of those who die from the disease is eighty (Figure 1)[4]. The public health burden of treating older men with both early and late prostate cancer is already substantial and will increase over the coming decades.

Since 2010, the International Society of Geriatric Oncology (SIOG) has produced several guidelines on prostate cancer management in older patients[5-8]. Although the literature reviews on which these guidelines were based were not systematic, they represented an expert multidisciplinary consensus. A major part of their purpose was to introduce the basics of geriatric frailty screening into urology and oncology departments. These guidelines used an age of 70 years to define older patients.

The first SIOG paper [5]reviewed the most important geriatric factors used in the process of making treatment decisions, i.e. dependence, comorbidities and nutritional status. Its most important conclusion was that treatment should not be based on chronological age but on health status as established by screening using different tools and evaluated by Comprehensive Geriatric Assessment (CGA). The Task Force also introduced the concept of geriatric intervention. This led the same year to the first set of SIOG recommendations[6].

The updated 2014 guidelines[7]introduced the G8 screening tool [9] to identify patients likely to benefit from a simplified geriatric evaluation or, in some cases, from a CGA in a geriatrics unit.

The 2017 update incorporated two important aspects not previously considered: the screening of cognitive impairment (using the mini-COG ${ }^{\mathrm{TM}}$ tool), and the early introduction of palliative care .[8]

A second important step was the full endorsement of the SIOG guidelines by the European Association of Urology, such that the recommendations are now referred to as the EAU/ESTRO/SIOG guidelines. 2017 also saw the dissemination within the urological community of a statement on the role of geriatric oncologists in optimizing care of urological oncology patients [10]. In this context, we can note that the EAU and SIOG are also currently co-operating on guidelines on the management of bladder cancers in older patients. 
Since prostate cancer and geriatric oncology are both rapidly evolving fields, SIOG in 2018 convened another Task Force. This had the aims of updating information on the active management of advanced prostate cancer and in supportive care, and discussing likely developments in management. This latter topic was broad and included surgery, minimally invasive therapies and surveillance, external beam radiotherapy and brachytherapy, review of health status evaluation, and geriatric oncology considerations in low and middle income countries. These guidelines are shown in Table 1.

Chairs of the SIOG Task Force performed searches via Medline and PubMed using the terms "prostate cancer", "neoplasms", "elderly", "age limit $>70$ years" and "metastatic prostate cancer" Papers selected were in English, focusing on the period since 01/06/2016 (the cut-off date of the literature search for the 2016 SIOG guidelines[8]) to 30/06/2018. 185 articles were selected based on abstract review. Section authors chose from this selection and added articles and abstracts they considered significant. Abstracts of the following meetings were also reviewed for relevant studies: EAU, ESMO, ASCO-GU and ASCO 2017 and 2018 annual meetings.

The members of the writing committee developed a first draft which was commented on by the reviewing committee and amended. Consensus was reached by the review process between July and August 2018. All authors approved the final version. All authors approved the final version.

As in previous articles, we use the D'Amico classification to define risk groups in localized prostate cancers[11]. We do not discuss in depth the geriatric evaluations described in previous guidelines[6$8]$, but we point out difficulties encountered with health status evaluation.

\section{Evaluation of general health status}

Treatment decisions in older patients with prostate cancer should not be guided by chronological age but by biological age and fitness [10]. To distinguish fit from unfit patients, physicians commonly use a standard clinical assessment and Eastern Cooperative Oncology Group Performance Status (ECOG PS)[12]. Identification of fitness and estimation of risks of treatment may be improved by CGA[13]. For this reason, SIOG strongly recommends the integration of CGA into the care plan of older patients with cancer[14].

However, the CGA of all older patients with prostate cancer may be hampered by lack of time or trained staff, the absence of a geriatrics department on site, and cost. It is probably not necessary to complete a CGA in all older patients [15]. For this reason, a rational three-step model of GA has been proposed: geriatric screening of all patients to identify those who need further assessment; GA in those patients with an abnormal result on screening; and geriatric interventions based on results of the CGA. As health status changes with time and prostate cancer progression, it should be reassessed at each step of patient management.

\section{Geriatric screening}

A screening tool is a brief assessment conducted to help identify which patients need further evaluation by GA. In a comprehensive review of different screening tools, the G8 (Table 2) was the most robust $[9,16]$. The eight-item $\mathrm{G} 8$ tool was specifically developed for older patients with cancer and covers food intake, body mass index, mobility, neuropsychological problems, polypharmacy, self- 
perceived health status and age. The maximum score is 17 and a score of 14 or lower is considered abnormal [9]. Importantly G8 screening is also recommended in the EAU guidelines [17].

In addition to the G8, the 2017 SIOG guidelines [8] recommended screening of cognitive function by the Mini-COG ${ }^{\mathrm{TM}}$. Where the result is abnormal, there should be a full cognitive assessment of the patient's capacity to evaluate information and make informed decisions. In a meta-analysis of studies that compared the validity of ten cognitive screening tools using the Mini Mental State Examination (MMSE) as reference, [18] the mini-COG ${ }^{\mathrm{TM}}$ most closely matched the MMSE[19]. The Mini-COG ${ }^{\mathrm{TM}}$ consists of three-word recall and a clock drawing test and can be completed within 5 minutes. A cutoff point of $\leq 3 / 5$ indicates a need to refer the patient for full evaluation of potential dementia. (Table 3)

\section{Comprehensive Geriatric Assessment}

Patients with an abnormal G8 score $(\leq 14 / 17)$ should have a full GA. This gold standard for geriatric health status assessment[20] is a multi-dimensional, interdisciplinary diagnostic process to identify care needs, plan care, and improve outcomes in frail older patients[21]. CGA covers several domains not covered by traditional medical assessment. These include functional status, fatigue, comorbidity, cognition, mental health status, social support, nutrition, and geriatric syndromes[22]. In older patients admitted to hospital, CGA has demonstrated a beneficial effect on survival, quality of life (QOL) and rates of institutionalization[22]. In older patients with cancer, CGA predicts survival and chemotherapy-related toxicity, identifies reversible conditions for which interventions may be needed, may influence choice of treatments, and reflects patients' capacity to make decisions as well as their values and treatment goals[14].

\section{Geriatric interventions}

CGA needs to be followed by interventions implemented in response to any vulnerabilities identified[23]. These interventions should be guided by a multidisciplinary team including medical specialists, nurses, psychologists, social workers, nutritionists, occupational therapists, physical therapists and pharmacists. An expert consensus algorithm for GA interventions has been published[24]. However, a prospective observational Belgian study demonstrated that only $46 \%$ of proposed interventions were actually implemented[25]. Currently, while CGA followed by interventions is recommended for all older adults with cancer, there have only been a handful of pilot intervention studies of clinical effectiveness[26-30]. Recently, a randomized controlled trial demonstrated that conducting a CGA improved communication in older patients with cancer[31]. The Clinicaltrials.gov database (accessed April 2018) showed 145 current studies that include CGA, with many of them open to patients with any solid tumour[32]. Once completed, these studies will add to the evidence base on the effectiveness of CGA in improving clinical outcomes.

\section{Future developments in health status evaluation}

With the worldwide increase in the number of older people with cancer, a shortage in specialists trained in geriatrics is inevitable. Thus there is a need for basic geriatric competency in all health care providers. One way to address the shortage of geriatric teams is the development of electronic assessments to assist CGA[30].

Older adults are interested in using technology to help manage their health[33-36]. The US Pew Research Center's latest data show that in 2016, 67\% of Americans aged 65 and over used the Internet. This figure ranged from $44 \%$ in those aged 80 and over to $82 \%$ in those aged $65-69$ years. Forty-two percent owned a smartphone and $32 \%$ a tablet[37]. 
Two recent reviews of mobile health interventions and telehealth self-management for older adults with chronic disease concluded that these approaches benefit communication, support the decisionmaking process and patient education, and improve clinical outcomes[38,39]. The use of technology would allow older adults to complete CGAs in their home before and between appointments and thus increase their availability. Furthermore, an online CGA would allow triaging of older adults with complex needs to geriatric experts, so optimizing scarce resources. Such an online tool could be coupled with feedback for oncology team members and patients to improve the care plan.

While two recent articles reviewed several systems for remote symptom and activity monitoring [40], fewer tools have been developed for the conduct of an online CGA[41]. To date, three online CGAs have been tested[42-44]. The first two studies included small numbers (38 to 100) but demonstrated high completion rates, with 51 to $92 \%$ of patients able to complete CGA independently. One of the two studies compared computer-based with pen and paper measures and found both could be completed in about 15-16 minutes. Two-thirds of participants preferred the computer-based assessments. The third CGA tool tested is the electronic Rapid Fitness Assessment (eRFA) developed by Shahrokni et al[44]. The eRFA consists of 65 items and includes a scoring algorithm. For the first 636 assessments completed, the median age was 80 years, and the median time to completion was 11 minutes[44]. Only $13 \%$ of patients needed help to complete the eRFA, and $90 \%$ felt it was easy to answer the questions[44]. Thus, while there is a lack of effectiveness data for these online tools, three studies suggest that they can be implemented in a busy oncology clinic. Further studies are needed to test these interventions on a larger scale to understand their clinical and cost-effectiveness.

Question arising from previous SIOG recommendations on health status evaluation

Health status screening as described in the 2017 SIOG prostate cancer recommendations[8] was based on the Mini-COG ${ }^{\mathrm{TM}}$ and G8 tools. Patients were divided into three health status groups based on comorbidities, functional status and nutritional status. The potential reversibility of health status impairments was taken in account in the decision making process. Although categorizing patients is difficult since there is a continuum between fit and frail, a recent study[45] demonstrated that the classification used in the 2014 guidelines was slightly (though not significantly) better in predicting one-year survival than the earlier Balducci criteria (fit-vulnerable-frail). The updated 2017 guidelines classified patients as fit, frail or disabled/with severe comorbidities, which better matches geriatric definitions.

Three questions emerge; and our discussions suggest we are still some distance from having answers: 1 ) is there any evidence that classifying older patients with prostate cancer is a valid means of decision making? The answer is uncertain, since we lack high-quality trials or prospective observational studies. 2) Which definition of "frailty", and which threshold, should we use when making decisions? There is still no good, evidence-based definition. 3) What is the definition and spectrum of "reversibility" and its impact on survival? Several studies are on-going, but we have no evidence-based data that demonstrate effects on survival.

The recent ASCO guidelines[46] on integrating GA into daily practice with older patients receiving chemotherapy recommend use of a validated tool listed at ePrognosis[47] to estimate non-cancer specific life expectancy, particularly in the adjuvant/curative setting. For example, the Schonberg and Lee Indices seem well validated. These indices include comorbidities but also functional status. The other recommendations are to include a screening tool (such as G8), geriatric evaluation using different screening tools, and eventually the CGA[46]. 
In short, it is desirable to use some form of geriatrics approach; to promote research on algorithms to help decision making and on the impact of geriatric interventions on the treatment decision; and to strictly define in these patients both frailty and the reversibility of health status impairments.

The Task Force therefore decided to adapt the former SIOG guidelines in the light of the ASCO recommendations, and to define and reword the decision making steps:

As a first step, older patients with prostate cancer should be screened using the G8 and miniCOG $^{\mathrm{TM}}$.

$>$ In the setting of early prostate cancer, we recommend use of ePrognosis[47] to estimate non-cancer specific life expectancy, and particularly the Schonberg and Lee Indices, to aid decision-making.

> Use of a frailty index guided by GA and frameworks where GA stratifies older patients into fit, vulnerable or frail groups, predicts mortality[46]. The SIOG Task force decided to continue to use the 2014 categories of: 1 Fit, defined by a G8 screening score of $>14 / 17$, no comorbidities, no dependence, no malnutrition and no cognitive impairment; 2 Vulnerable, where patients have either some impairment in Activities of Daily Living (ADL) or moderate malnutrition or moderate comorbidities; and 3 Frail, where older patients are either dependent in multiple ADLs or have severe malnutrition or severe comorbidities. All vulnerable and frail patients are likely to benefit from CGA and interventions.

\section{Surgery, focal therapy and surveillance}

\section{Treatment is based on risk}

Treatment decisions should take into account the risk of dying from prostate cancer (i.e. tumour grade and stage), the risk of dying from another cause (i.e. comorbidities), the risks of treatment, and patient preferences. In the three previous guidelines, only older patients with D'Amico high-risk and some selected intermediate-risk prostate cancer patients were considered candidates for curative local treatment. Patients with low-risk prostate cancer were not.

Healthy older patients with high-risk prostate cancer are often undertreated. At the other end of the spectrum, there is concern regarding overtreatment and ensuing morbidity in low-risk patients with comorbidities and limited life expectancy. It is imperative to assess the benefit to risk ratio, with the latter including erectile dysfunction and incontinence.

The ProtecT study shed light on low and potentially intermediate risk disease[48]. Patients with a screening detected prostate cancer ( $60 \%$ low-risk, $40 \%$ intermediate-risk and a few high-risk) were randomized between radical prostatectomy (RP), external beam radiotherapy (EBRT) plus six months of androgen deprivation therapy (ADT), or active monitoring. This was a 'light' active surveillance protocol with repeat biopsy at DRE-based clinical progression, or a PSA rise of more than $50 \%$ in 12 months. 
At 10 years, there was no difference in disease specific survival between the three arms. Although cases of metastasis were few $(<10 \%)$ in all arms, the active treatment arms had a delay of disease progression and lower incidence of metastases. QoL impact was assessed using Patient-Reported Outcomes after Monitoring (PROMs) [49]. No overall difference in QoL was observed between the 3 modalities while the lower frequency of specific side effects (urinary, sexual and digestive) clearly favored surveillance.

This trial demonstrates the harm of overtreatment, in terms of cost, and increased morbidity. This is especially so in the case of older low risk prostate cancer patients, and probably even in intermediate risk disease.

\section{Radical prostatectomy (RP)}

Older men are more likely to be diagnosed with high risk localized prostate cancer and may thus benefit more from a local treatment including RP. In high risk disease, cancer-specific survival is up to $91 \%$ with surgery combined with adjuvant and/or salvage modalities. Survival can be up to $95 \%$ with one risk factor (ie Gleason $>7$ or T $>$ T2 or PSA $>20 \mathrm{ng} / \mathrm{ml}$ ), and 79\% with three[50].

Only one randomized clinical trial comparing RP to watchful waiting (WW) showed a survival benefit for those having surgery[51]. This trial was conducted before measurement of PSA was routine, with only $12 \%$ of patients being T1c, and with a mean PSA level of $13 \mathrm{ng} / \mathrm{ml}$ (when reported). The updated results from the PIVOT trial with close to 20 years follow up[52] did not show any survival benefit for RP for patients with localized low and intermediate risk disease, questioning the value of RP even in patients with at least 20 years of life expectancy. However the patient selection in this trial has recently been questioned. Regarding the surgical approach, no benefit from any particular route has been observed[53].

\section{Minimally invasive therapies}

Hemi-gland ablation or ablation of the index lesion(s) in older patients with prostate cancer remains experimental though promising[54]. Options include high intensity focused ultrasound (HIFU), cryotherapy, photodynamic and laser therapy, and irreversible electroporation. The only phase 3 randomized clinical trial of focal therapy used a photodynamic compound (Padeliprofin) and an interstitial laser to activate the product, compared to active surveillance (AS)[55]. The major limitation of this positive trial -- based on negative prostate biopsies at 24 months -- is the inclusion of the lowest risk group patients in whom AS is considered standard of care in recent guidelines. Therefore, although EMA-approved, it may be of limited value, especially as far as older adults are concerned.

\section{Watchful waiting and active surveillance}


Patients with low-risk disease are likely to benefit from watchful waiting (i.e. expectant management) or active surveillance, with curative intervention delayed until progression. The key driver in choosing between the two approaches is individual life expectancy. An intermediate way could be active monitoring for those with only 10 years life expectancy, based on the ProtecT results, where active surveillance might be considered over-treatment. Several guidelines now consider that AS should be standard of care for most patients with low risk disease, and for some with intermediate-risk disease, especially if mainly based on PSA[56].

It is worth noting that many older men have lower urinary tract symptoms, often related to benign prostatic hyperplasia, that need to be clearly distinguished from a contemporaneous carcinoma. In such cases these symptoms should be managed separately from cancer following proper recommendations. 


\title{
External radiotherapy and brachytherapy
}

\author{
Radiotherapy
}

Image-guided Intensity-Modulated Radiotherapy (IMRT) is now standard of care for localized or locally advanced prostate cancer treated with EBRT. This technique uses computer assisted technology to modify and shape the intensity of radiotherapy beams during treatment to deliver very precise coverage of the target area. It reduces radiation exposure of surrounding normal tissues (bladder, bowel, and rectum), which had previously limited the dose that could be given without unacceptable side effects.

\section{Hypofractionation}

Hypofractionation (delivering fewer treatments at a higher dose per treatment) was well demonstrated in the CHHIP trial comparing standard RT fractionation (37 fractions over 7.5 weeks) to 20 fractions over 4 weeks. Five year biochemical control rate was non-inferior in the trial arm[57]. Similar results were achieved in the HYPRO study[58]. Further studies have demonstrated good biochemical control rates in high[59], medium[60] and low[61] risk prostate cancer. However, the low risk study reported an increase in late Grade 2 and 3 genitourinary and gastroenterological toxicities[61]; and the routine use of radiation in low-risk disease is not recommended.

None of these studies was tailored to the older population although all included a proportion of patients aged over 70 years. Hypofractionation offers distinct advantages to both patients and radiotherapy units in reducing overall treatment time and the number of visits needed to complete therapy. Available data do not make clear whether there are any therapeutic advantages or risks specific to older prostate cancer patients.

\section{Dose escalation with brachytherapy}

Brachytherapy also exploits the potential benefit of a smaller number of dose fractions. Ongoing trials have highlighted the role of both permanent low dose rate (LDR) and temporary high dose rate (HDR) brachytherapy given as a 'boost' dose or alone as monotherapy.

The use of a single HDR brachytherapy boost in conjunction with EBRT is supported by a growing body of evidence and is now frequently used in both intermediate- and high-risk disease[62,63]. The ASCEND-RT (Androgen Suppression Combined with Elective Nodal and Dose Escalated Radiation Therapy) trial compared dose escalation to $78 \mathrm{~Gy}$ with an LDR boost following an external beam 
radiotherapy dose of $46 \mathrm{~Gy}$. The LDR boost cohort were twice as likely to be free of disease at $6.5 \mathrm{yr}$ follow up[64], although this was at the expense of increases in both clinician and patient reported toxicity $[65,66]$. The median ages were 69 in the dose escalation and 67 in the LDR-boost arms respectively. However, the age range in both arms extended to above 80 , suggesting some relevance to older patients.

HDR brachytherapy as sole treatment is experimental but can be given in a single session or fractionated, with a number of lower dose insertions. A recent phase 2 study[67] of 283 men reported that a single HDR brachytherapy dose of 19-20Gy achieves rates of late morbidity and biochemical control similar to those following $2(2 \times 13 \mathrm{~Gy})$ and 3 fractions $(3 \times 10.5 \mathrm{~Gy})$. Although this study does not report age-specific outcomes, a single insertion would potentially be associated with fewer toxicities including those related to anesthesia, which may be especially relevant in older patients. The results of further HDR brachytherapy studies are awaited.

\section{Areas of ongoing development in RT}

The ability to dose escalate or hypo-fractionate has clear advantages for patients, but there remains concern about increased long-term toxicity. Advances in prostate RT delivery, such as rectal spacer insertion prior to IMRT[68], demonstrate reduced post-treatment rectal toxicity. However, this study included mainly younger men (mean age 64yrs in the spacer group). Ongoing studies are assessing the potential advantages of a rectal spacer in older patients. Dose escalation studies using stereotactic RT have yielded initially encouraging results[69] but its use remains experimental.

\section{Medical treatment}

\section{Non metastatic castration resistant prostate cancer (MOCRPC)}

Currently, two drugs are approved in this setting based on recent studies that included patients receiving ADT with a PSA doubling time of 10 months or less, a PSA value $>2 \mathrm{ng} / \mathrm{ml}$ and no evidence of metastatic disease based on bone or CT scan or nodal involvement (lymph nodes with a short axis $<2 \mathrm{~cm}$, below the iliac bifurcation were allowed).

In the SPARTAN trial[70], patients (median age 74 years) were randomized 2:1 to receive apalutamide, a novel competitive inhibitor of the androgen receptor, or placebo. After the first detection of distant metastasis, patients were eligible to receive treatment with abiraterone plus prednisone. The primary endpoint was metastasis-free survival (MFS). The median MFS was 40.5 months in the apalutamide group vs 16.2 months with placebo $(p<0.001)$. Benefit was seen in all subgroups, including patients over 75 . Progression-free survival (PFS), time to symptomatic progression and time to chemotherapy initiation were also longer with apalutamide. Overall survival (OS) data are not yet mature. The second PFS (on second line treatment after apalutamide/placebo) was significantly longer in the apalutamide group than in the placebo group. Toxicity was 
manageable. Grade 3 or 4 adverse events (AEs) occurred in $45.1 \%$ of patients on apalutamide and $34.2 \%$ of those on placebo. The most frequent AEs related to apalutamide were fatigue (30.4\%) and rash (23.8\%). Other treatment-related AEs were falls, fractures and hypothyroidism. Falls and fractures can have a major impact on the independent living of older patients. However, QoL outcomes favored apalutamide.

In the PROSPER trial[71], patients were randomized 2:1 to receive enzalutamide or placebo. The median age was again 74 years. Median MFS was 36.6 months in the enzalutamide group vs 14.7 months with placebo $(p<0.001)$. Benefit was seen in all subgroups including older patients. Time to PSA progression and time to new antineoplastic treatment were also longer with enzalutamide. Grade 3-4 AEs occurred in $31 \%$ of patients on enzalutamide and $23 \%$ on placebo. The most frequent AEs of interest on enzalutamide were hypertension (12\%), cardiac events (5\%) and mental impairment disorders (5\%). Fatigue occurred in 33\% of patients and Grade 3-4 fatigue in 3\%. Eleven percent of patients had a fall. Enzalutamide did not lead to worsening QoL and significantly reduced the risk of clinically meaningful QoL deterioration in several FACT-P domains[72], but toxicities were not reported by age group in this study. Data from the PREVAIL trial show that only falls were increased in elderly patients with enzalutamide.[73]

A third drug has shown in a phase III trial a benefit in the same situation.[74] Darolutamide is a novel androgen-receptor antagonist that has negligible blood barrier penetration and low potential for drug-drug interaction. Patients were randomized 2:1 to darolutamide or placebo. The median age was again 74 years. Median MFS was 40.4 months in the darolutamide group vs 18.4 months with placebo $(p<0.001)$. Benefit was seen in all subgroups including older patients. Overall survival, time to pain progression, time to cytotoxic chemotherapy, and time to a symptomatic skeletal were improved in the darolutamide arm. Grade 3-4 AEs occurred in $24.7 \%$ of patients on darolutamide and $19.7 \%$ on placebo. Darolutamide was not associated with a higher incidence of falls, fractures, cognitive disorder, or hypertension than placebo, this is of special interest in older patients. Quality of life was not negatively affected by darolutamide.

\section{Newly diagnosed metastatic castration-sensitive disease (Table 4)}

\section{New hormonal treatments}

In men with de novo metastatic castration-sensitive prostate cancer (mCSPC), two studies have demonstrated a benefit from adding abiraterone to standard ADT. The LATITUDE trial compared abiraterone 1,000 mg + 5mg prednisone + ADT to double placebo + ADT in patients with newly diagnosed metastatic prostate cancer $[75,76]$. The study enrolled only patients with high-risk disease, defined as having at least 2 of the following features: Gleason score $\geq 8$, more than 3 bone metastases, presence of measurable visceral disease. Median age was 68 years (range $33-92$ ) with $41 \%$ of patients aged $\geq 70$ and $20 \% \geq 75$. The co-primary endpoints were OS and radiological progression free survival (rPFS). Both were met. The HR for OS was 0.62 (IC $95 \%=0.51$ to 0.76 ; 
$\mathrm{p}<0.001)$ favoring abiraterone. Median OS was 30.4 months with placebo and was not reached in the abiraterone arm. The trend for better OS was seen in all age groups: < 65 (HR: 0.62); $\geq 65$ (HR: 0.64) and $\geq 75$ years (HR: 0.82 ). The trial was not powered to determine whether benefit varied by age Toxicity was not detailed by age. Less than half of the patients in the placebo group received new hormonal agents.

Data from the abiraterone arm of the STAMPEDE trial have also been published[77].The trial had a more heterogeneous population than LATITUDE since it enrolled patients with newly diagnosed metastatic or $\mathrm{N}+$ prostate cancer, patients with newly diagnosed locally-advanced high-risk disease (with at least 2 of the following: T3/T4, PSA $\geq 40 \mathrm{ng} / \mathrm{mL}$, Gleason score $\geq 8$ ), and patients relapsing after local treatment ( $\mathrm{M}+, \mathrm{N}+, \mathrm{PSA} \geq 20 \mathrm{ng} / \mathrm{mL}$ or PSA $\geq 4 \mathrm{ng} / \mathrm{mL}$ and PSA doubling time $<6$ months). Forty nine percent of patients had newly diagnosed metastatic disease. Median age was 67 years (range $39-85$ years). More than $37 \%$ of patients were $\geq 70$ years old. Patients with significant cardiovascular comorbidity were excluded. In this study, adding 1,000 mg abiraterone $+5 \mathrm{mg}$ prednisolone to ADT improved survival ( $H R=0.63$ (IC $95 \%=0.52$ to $0.76 ; P<0.001)$ ). In men over 70 years, the HR for OS was 0.94 (0.69-1.29). The rate of grade 3-5 toxicity with abiraterone was similar in patients aged below 70 vs seventy and above ( $46 \%$ vs $48 \%$ ).

A meta-analysis performed by the STOPCaP collaborators [78]included patients from LATITUDE and those with newly diagnosed metastatic prostate cancer from STAMPEDE. Results showed a highly significant $38 \%$ reduction in the risk of death with abiraterone plus ADT that translates into a $14 \%$ absolute improvement in 3-year OS.

A further STAMPEDE study compared standard of care for metastatic prostate cancer with and without radiotherapy of the primary[79]. Evidence suggests that prostate radiotherapy improves OS for men with metastatic prostate cancer who have a low metastatic burden in the pre-specified subgroup analysis (HR 0.68, 95\% Cl 0.52-0.90; $\mathrm{p}<0.007$ ), but not for unselected patients. Prostate radiotherapy should be a standard treatment option for men with newly diagnosed disease with a low metastatic burden. However data were not detailed by age groups.

\section{Long-term results of chemotherapy}

The most recent update[80]from the CHAARTED trial confirms the improvement in OS achieved by adding docetaxel to ADT in MCSPC: median OS 57.6 months versus 47.2 months for ADT alone (HR= $0.72 ; 95 \% \mathrm{Cl}, 0.59$ to $0.89 ; \mathrm{p}=.0018$ ), although the magnitude of the benefit is less than originally published, and more in line with data from the similar trials GETUG-15[81] and STAMPEDE[82]. OS benefit was greater in "high-volume" ( $\geq 4$ bone metastases with at least one beyond the spine or pelvis and/or visceral metastases) than "low-volume" disease. This trend is confirmed in the aggregate analysis of GETUG 15 and CHAARTED. [83,84]The benefit of adding docetaxel was seen both in patients under and over 70 years of age[84]. It is noteworthy that GETUG 15[81] included only patients aged 70 or less, although the trial was included in the combined analyses. 
Several questions remain. Should every MCSPC patient receive either abiraterone or docetaxel? Is one better than the other? If so, how should we choose between them, or should they be combined? What treatment should be given at progression? $[85,86]$ Fortunately, there are data to shed light on these uncertainties[87].

In the STAMPEDE trial, the docetaxel and abiraterone arms recruited concurrently over a period of 17 months, during which 566 patients were enrolled[88]. An opportunistic comparison between the two arms shows no significant difference in overall or prostate cancer-specific survival. However, network meta-analysis comparing treatments for MCSPC suggests that abiraterone has the higher probability of being the more effective treatment in both OS (89-94\% probability) and failure-free survival ( $100 \%$ probability)[89]. Whether this remains true in older patients is difficult to determine since only $29 \%$ of those enrolled were aged more than 70 years.

Further questions relevant to age concern the specific AEs associated with adding docetaxel or abiraterone in patients with heterogeneous health status. Patients in the abiraterone phase 3 trials were generally older than those in the docetaxel phase 3 (median age 68 vs 64 years). However, all were selected as having excellent performance status. When the three randomized trials related to ADT + docetaxel[82,84,90] are considered, the principal grade 3-4 toxicities are neutropenia in $15 \%$, febrile neutropenia (FN) in 10\%, fatigue in $5 \%$, and cardiovascular events in $3 \%$, Nail changes and neuropathy were seen in $<1 \%$. There were only five toxic deaths in a total of 1178 patients. No information is provided in older patients with $\mathrm{mCSPC}$. Nevertheless it is noteworthy that in mCRPC TAX 327, docetaxel toxicity was slightly higher in older age groups. This was particularly so for neutropenia-related outcomes in Horgan et al.'s secondary analysis of TAX327[91]; and the challenges in using docetaxel in the frail elderly are well recognized[92].

\section{Metastatic castration resistant prostate cancer (mCRPC)}

No new drugs have been approved for mCRPC since the 2017 guidelines [8]. Cabazitaxel has been approved for several years for MCRPC progressing after docetaxel. The FIRSTANA trial showed that it was not better than docetaxel in first line[93], although OS was not different; and toxicity was less when used at $20 \mathrm{mg} / \mathrm{m}^{2} /$ cycle versus $25 \mathrm{mg} / \mathrm{m}^{2}$. In second line, the PROSELICA phase III noninferiority trial compared cabazitaxel $25 \mathrm{mg} / \mathrm{m}^{2}$ (standard dose) to a reduced dose $\left(20 \mathrm{mg} / \mathrm{m}^{2}\right)$ [94]. Cabazitaxel $20 \mathrm{mg}$ was non-inferior in OS in the intent to treat population (primary objective). The median age of patients was 68 , and results did not differ according to age. Grade $\geq 3$ adverse events were less frequent with cabazitaxel $20 \mathrm{mg} / \mathrm{m}^{2}$ (39.7\% vs $54.5 \%$ ). This reduced dose should be used in second-line chemotherapy, especially in older patients.

For patients with $\mathrm{mCRPC}$, two studies of modified schedules of cabazitaxel have been published. The SOGUG[95] published a phase II trial of weekly cabazitaxel $10 \mathrm{mg} / \mathrm{m}^{2}$ on days $1,8,15$ and 22 of a 5week cycle in seventy "unfit" patients (either PS2 or previous FN with docetaxel or RT involving > $25 \%$ of bone-marrow). Patients' median age was 74 years, $71 \%$ were PS2, $13 \%$ had experienced FN and $19 \%$ had had extensive RT. The median OS was 12.6 months ( $95 \% \mathrm{Cl}: 8.2-17.1 \%)$. The most 
frequent toxicities were asthenia (40\%), diarrhoea (37\%), anorexia (30\%) nausea (27\%), and peripheral neuropathy (18\%). There was no FN or grade 4 diarrhoea.

Clement-Zhao et al[96] report on a regimen of cabazitaxel $16 \mathrm{mg} / \mathrm{m}^{2}$ every 2 weeks with G-CSF support. In their pilot study on 43 patients, median age was 70 and $27 \%$ were ECOG PS $\geq 2$. Fourteen percent stopped treatment because of toxicity. Grade $\geq 3$ toxicity occurred in $35 \%$ of patients, with FN in $4.7 \%$. Median OS was 15.2 months (95\% $\mathrm{Cl}=9.9-19.1$ ). Phase III trials (such as CABASTY) comparing cabazitaxel $25 \mathrm{mg} / \mathrm{m}^{2}$ every three weeks to cabazitaxel $16 \mathrm{mg} / \mathrm{m} 2$ biweekly in older patients are needed to confirm these results. Further studies of a weekly schedule are also desirable.

\section{Future developments}

There are still many questions concerning the best means of treating patients with metastatic prostate cancer, particularly older patients. Nevertheless, irrespective of age and health status, abiraterone and enzalutamide should not be used consecutively since there is a high rate of crossresistance, whereas taxanes remain active in patients pretreated with new hormonal agents.

To date, no biomarkers are ready for routine use although there is ongoing work on Circulating Tumour Cells (CTC) counts, CTC characterization (AR variants, mutations), cell free DNA, and miRNA as predictors of response[97].

Increased understanding of the underlying molecular pathology, such as in DNA repair[98,99], has led to trials with targeted therapies. PARP inhibitors have shown contrasting results: olaparib showed efficacy in heavily pre-treated patients, mainly in those with DNA repair alterations[99]; but combining velaparib, which may be a less powerful PARP inhibitor, with abiraterone was not better than abiraterone alone[100]. In a phase II trial, olaparib in combination with abiraterone improved rPFS compared to placebo plus abiraterone in MCRPC[101] : median 13.8 vs 8.2 months; HR=0.65 (IC95\%=0.44-0.97). Benefit seemed independent of homologous DNA repair gene status. However, grade 3 toxicity rate - especially cardiovascular -- was higher in the combination arm ( $53 \%$ vs $28 \%$ ).

In relation to immunotherapy, the two trials with ipilimumab (in chemo-sensitive patients as monotherapy, or in combination with bone-directed RT in patients previously treated with docetaxel) did not meet their primary OS endpoint although PFS was improved[102,103]. Several trials are ongoing with anti-PD-L1/PD-1 monotherapy or in combination with anti-CTLA 4 antibodies, new hormonal agents, or targeted therapies such as PARP inhibitors. Two phase 2 trials reported activity with anti-PD-L1 agents in enzalutamide pre-treated men, probably due to the expression of PDL1 induced by enzalutamide therapy[104]. The phase 2 trial of pembrolizumab monotherapy reported low objective response rates $(\leq 6 \%)$ and a disease control rate of $22 \%$ in patients with predominantly bone metastases[105]. Experience of immunotherapy in older patients with urological tumours [106] and melanoma[107] suggests that benefits in older patients are similar to those in younger patients, 
and - although little evidence is available - it appears that toxicity is no greater. Trials conducted specifically in older patients are needed.

\section{Radiopharmaceuticals}

Radiopharmaceuticals are generally less toxic than chemotherapy and so may be especially relevant to older patients[108]. Recent analyses from the ALSYMPCA trial of Ra-223 and from the early access programme confirm its positive impact on bone related complications with decreased hospitalizations and an overall favorable toxicity profile even in older patients [109-111]. However preliminary results from combination trials have shown unexpected toxicity (high rates of fractures in combination with abiraterone/prednisolone)[112]. The EMA's safety committee PRAC has recommended restricting use to patients who have had two previous treatments for bone metastases or who cannot receive other treatments. The PRAC also confirmed its interim recommendation that Ra-223 must not be used with abiraterone acetate and prednisone/prednisolone. Ra-223 should not be used with other systemic cancer therapies, except for ADT. New radiopharmaceuticals such as 177Lu-PSMA617[113] are in development. Phase 2 trial in older patients demonstrates clinical effect, PSA decline and few side effects. However phase 3 trials are needed to compare this agent against standard treatments.

\section{Supportive care}

The 2016 SIOG recommendations introduced the importance of including early supportive care and -in advanced disease -- early palliative care in the management of older patients with prostate cancer[8]. This is an important part of patient management.

\section{Managing side effects of androgen deprivation therapy}

ADT has many side effects $[114,115]$. These may include myocardial infarction and cerebrovascular disease, metabolic syndrome, diabetes, obesity, dyslipidemia, acute renal insufficiency, osteoporosis and fractures, hot flushes, sexual dysfunction, loss of libido, erectile dysfunction, cognitive impairments, and gynecomastia. The prevalence of these side effects can be high, with obesity in 50$80 \%$ of patients, metabolic syndrome in $20-40 \%$, osteoporosis in $25-40 \%$, and cardiovascular diseases in $15-25 \%$. A systematic review of prevention was published in 2013[116].

Cognitive impairment is an important concern and a baseline cognitive evaluation may be helpful to assess any effects of ADT. A recent systematic review and meta-analysis[117] showed that ADT was not associated with overall cognitive impairment in prospective studies. There was an increased risk of any cognitive impairment in retrospective studies, but this was not significant. Thus, there is a case for further studies. 
Impaired bone health is a potentially important side effect. Recommendations for monitoring and maintaining bone health[118] include baseline bone mineral density (BMD) testing with conventional dual X-ray absorptiometry. Denosumab $60 \mathrm{mg}$ subcutaneous injection every 6 months should be considered to reduce the risk of fracture in men at increased fracture risk (ideally identified with a validated tool such as the World Health Organization Fracture Risk Assessment). Bisphosphonates were effective in improving BMD, but the effect on fracture was inconclusive. However vitamin $D$ supplementation is recommended and, if dietary intake is low, supplementation with calcium[8].

The protective effects of exercise have been investigated[119]. Aerobic and resistance training improve cardiorespiratory fitness, muscle strength, physical function, body composition and fatigue. They may therefore counteract ADT-induced side effects. Prospective randomized trials of different exercise procedures on QOL, tolerance of treatment and adherence are justified[120].

\section{Managing other medical treatments in older patients}

Based on models of the haematological toxicity of chemotherapy in older patients, the 2014 SIOG guidelines[7] recommended G-CSF as primary prophylaxis [121,122]. This is compatible with current guidelines on the use of G-CSF[123]. Nevertheless use of G-CSF should be limited to older patients receiving chemotherapy who have had in-depth evaluation of frailty, balancing the benefit and harms[124]. Otherwise standard recommendations should be used.

The prevention of toxicities associated with new agents is an increasingly important consideration. With abiraterone in hormone sensitive metastatic prostate cancer[75], the most frequent grade 3-4 AEs were hypertension (seen in $20 \%$ of patients), hypokalemia (10\%), hyperglycaemia (4\%), elevated transaminases (4\%), and cardiac disorders (3\%), with some atrial fibrillation. In the LATITUDE trial, $20 \%$ of patients discontinued abiraterone because of side effects (vs $12 \%$ discontinuation in the placebo arm).

In the MCRPC trial[125], the spectrum of grade 3-4 toxicity showed less hypertension (1\%), but the same proportion of cardiac disorders, and more frequent fluid retention (2\%). However detailed information on patients' age and comorbidity is not available. It is important to perform an initial cardiac evaluation, to treat pre-existing high blood pressure, to correct hypokalemia, to monitor $\mathrm{CBC}$, ASAT/ALAT, hypokalemia, glycaemia and blood pressure.

With enzalutamide in MCRPC[126], the most frequent grade 3 side effects were fatigue (6\%) and -- in around $1 \%$ of patients -- diarrhoea, cardiac disorders, and seizure.

With both agents, there should be further prospective study of AEs - particularly those such as fatigue and mobility with particular impact on the elderly. In the context of polypharmacy, it is 
important to note that both abiraterone and enzalutamide interact with different substrates of cytochrome P450 and have the potential for adverse interaction with many frequently used prescription and non-prescription drugs[127].

\section{Geriatric oncology considerations in low and middle income countries}

In developing countries, cancers tend to be diagnosed at an advanced stage, treatment is limited by resources, and outcomes are generally poor. In these countries, the number of older patients with cancer will rapidly increase.

Table 5 shows that in 2040 the number of new prostate cancers in patients aged 70 and older in inter-tropical countries will be the same as in countries in the North. However the number of prostate cancer deaths will be greater in these countries due to late diagnosis and insufficient treatment.

Principles of contemporary geriatric oncology may not be easily implemented in developing countries due principally to a lack of geriatricians and education of health professionals.

A recent review[128] attempted to define the requirements to circumvent these difficulties. Recommendations were:

- Development of adapted screening tools of frailty

- $\quad$ Establishment of a decision-making process to suit resources and cultures and based on standardized and simple screening tools and clinical exam,

- $\quad$ Training of health professionals (MDs and others)

- $\quad$ Dissemination of scientific knowledge both in clinical and basic research.

This requires cooperation between northern/western institutions and those in other countries, and a global willingness to give older adult cancer patients in low and middle income countries access to adapted and active care based on efficiency and equity. Initiatives should be developed within the geriatric oncology community. Following the example of the NCCN harmonized guidelines for SubSaharan Africa[129], specific guidelines on the management of prostate cancer in older patients should be developed.

\section{Conclusion}

Driven by rapid developments in the treatment of prostate cancer and in geriatric oncology, SIOG undertook to update their guidelines on managing the disease in the older patients. The Task Force continues to recommend that patients should be treated on the basis of health status evaluation and not according to chronological age. Geriatric evaluation is based on a screening test of health 
impairment, then evaluation of dependence, comorbidities and nutritional status. When impairment is detected, patients may benefit from a comprehensive geriatric assessment. This allows the implementation of geriatric interventions likely to facilitate a more appropriate and effective treatment plan. The Tasks Force recommends screening for cognitive impairment using the mini$\mathrm{COG}^{\mathrm{TM}}$ and the early introduction of palliative care in cases of metastatic disease.

The Task Force recommends an in-depth evaluation of health status before the start of treatment at each significant change in the disease and its management. It therefore regards as mandatory some form of geriatric evaluation. It also focuses on the prevention of side effects and the potential protective role of adapted physical activity. Evaluation of the side effects of medical treatment in everyday practice and their impact on older patients warrant further research. Major problems encountered in prostate cancer in general have recently been outlined and may help focus research adapted to older patients[130].

Finally the Task Force recognizes the potential of health status self-evaluation using new technologies and the importance of developing guidelines applicable in inter-tropical countries in which the majority of older patients with prostate cancer will live by the year 2040.

Taskforce recommendations for the management of older patients with prostate cancer are summarized in Table 1. 


\section{Search strategy and selection criteria}

Chairs of the SIOG Task Force performed searches via Medline and PubMed using the terms "prostate cancer", "neoplasms", "elderly", "age limit >70 years" and "metastatic prostate cancer" Papers selected were in English, focusing on the period since 01/06/2016 (the cut-off date of the literature search for the 2016 SIOG guidelines[8]) to 30/06/2018. 185 articles were selected based on abstract review. Section authors chose from this selection and added articles and abstracts they considered significant. Abstracts of the following meetings were also reviewed for relevant studies: EAU, ESMO, ASCO-GU and ASCO 2017 and 2018 annual meetings.

\section{Contributors}

The SIOG Board (MA executive secretary) had the idea and designated HB and J-PD to chair the Task Force. Members were chosen by J-PD and MA and allocated to different sections: Stéphane Oudard and Karim Fizazi (France) medical oncology; Nicolas Mottet (France) urology; Heather Payne and Mark Prentice (United Kingdom) radiation oncology; Martine Puts (Canada) and Lore Decoster (Belgium) geriatric oncology; and to the reviewing committee: Eleni Efstathiou (USA) medical oncology and Shabbir Alibhai (Canada) geriatric oncology.

The members of the writing committee developed a first draft which was commented on by the reviewing committee and amended. Consensus was reached by the review process between July and August 2018. All authors approved the final version.

Acknowledgments: Editorial support was provided by Rob Stepney (medical writer, Charlbury, UK) and funded by SIOG (International Society of Geriatric Oncology)

\section{Conflict of Interest statement}

$\mathrm{H}$ Boyle has received travel expenses from BMS, Pfizer, Jansen, Astellas, Sanofi, Ipsen and honoraria from Sanofi, Novartis, Janssen, Ipsen, Pfizer.

\section{S Alibhai: none}

L Decoster has received travel grants and research support from Roche, BMS, MSD, BoeringherIngelheim.

E Efstathiou has received Grants/research from Sanofi Jannsen, Astellas, Pfizer; honoraria/advisory boards from Sanofi, Bayer, Janssen, Astellas, Takeda, Tolmar.

$\mathrm{K}$ Fizazi has taken part in advisory boards and received honoraria from Amgen, Astellas, Astrazeneca, Bayer, Curevac, Essa, Genentech, Janssen, MSD, Orion, Sanofi.

N Mottet has received grants/research support from Takeda/ Millenium, Astellas, Pierre Fabre, Sanofi, Pasteur and honoraria or consultation fees from Astellas, Janssen, BMS, Bayer, IPSEN, Ferring, Pierre Fabre, Roche, Sanofi, Steba.

S Oudard has received grants/research from Sanofi and Janssen; honoraria/advisory boards from Sanofi, Bayer, Janssen, Astellas.

H Payne has attended and received honoraria for advisory boards, travel expenses to medical meetings and served as a consultant for AstraZeneca, Astellas, Janssen, Sanofi Aventis, Takeda, Ipsen, Ferring, Sandoz and Novartis. 
M Prentice has received honoraria and travel expenses from Janssen.

M Puts: none

M Aapro was a consultant for Accord, Amgen, BMS, Celgene, Clinigen, Eisai, Genomic Health, GSK, Helsinn, Hospira, JnJ, Merck, Merck Serono, Novartis, Pfizer, Pierre Fabre, Roche, Sandoz, Tesaro,Teva, Vifor and he has received honoraria for lectures at symposia of Amgen, Bayer Schering, Biocon, Boehringer,Cephalon, Chugai, Eisai, DrReed, Genomic Health, Glenmark, GSK, Helsinn, Hospira, Ipsen, JnJ OrthoBiotech, Kirin Kyowa, Merck, Merck Serono, Novartis, Pfizer, Pierre Fabre, Roche, Sandoz, Sanofi, Tesaro, Taiho, Teva, Vifor

JP Droz has received travel expenses from Sanofi, Janssen and Roche; honoraria from Sanofi. 


\section{Figure legends}

Figure 1: Age distribution at diagnosis and death SEER Cancer Stat Facts4: Prostate Cancer. National Cancer Institute. Bethesda, MD, https://seer.cancer.gov/statfacts/html/prost.html

Figure 1a: Age distribution at diagnosis

Figure $1 b$ Age distribution at death

Figure 2: Decision tree to determine patient health status [8].

Legends: mini-COG ${ }^{\mathrm{TM}}$ : mini-COG ${ }^{\mathrm{TM}}$ cognitive test; ADL: Activities of Daily Living; CIRS-G: Cumulative Illness Rating Score - Geriatrics; CGA: Comprehensive Geriatric Assessment

For mini-COG ${ }^{\mathrm{TM}}$ a cutoff point of $\leq 3 / 5$ indicates a need to refer the patient for full evaluation of potential dementia

Figure 3: Decision making based on health status assessment [8].

Legends : G8; mini-COG ${ }^{\mathrm{TM}}$ : mini-COG ${ }^{\mathrm{TM}}$ cognitive test; $\mathrm{CGA}$ : Comprehensive Geriatric Assessment

For mini-COG ${ }^{\mathrm{TM}}$ a cutoff point of $\leq 3 / 5$ indicates a need to refer the patient for full evaluation of potential dementia 


\section{REFERENCES}

[1] International Agency for Reseach on Cancer (IARC), GLOBOCAN 2018. Estimated Cancer Incidence : age-specific tablese. Https://WwwUiccOrg/New-Global-Cancer-Data-Globocan20182018

[2] Wong MCS, Goggins WB, Wang HHX, Fung FDH, Leung C, Wong SYS, et al. Global Incidence and Mortality for Prostate Cancer: Analysis of Temporal Patterns and Trends in 36 Countries. Eur Urol 2016;70:862-74. doi:10.1016/j.eururo.2016.05.043.

[3] International Agency for Reseach on Cancer (IARC). Globocan 2018: estimated cancer incidence, mortality and prevalence worldwide in 2018. On line analysis: prediction. Cancer tomorrowle. Http://GlobocanlarcFr/Pages/Burden_selApx 2018.

[4] National Cancer Institute. SEERCancer Stat Facts: Prostate cancer. Https//SeerCancerGouv/Statfacts/Html/ProstHtml 20182018.

[5] Droz J-P, Balducci L, Bolla M, Emberton M, Fitzpatrick JM, Joniau S, et al. Background for the proposal of SIOG guidelines for the management of prostate cancer in senior adults. Crit Rev Oncol Hematol 2010;73:68-91. doi:10.1016/j.critrevonc.2009.09.005.

[6] Droz J-P, Balducci L, Bolla M, Emberton M, Fitzpatrick JM, Joniau S, et al. Management of prostate cancer in older men: recommendations of a working group of the International Society of Geriatric Oncology. BJU Int 2010;106:462-9. doi:10.1111/j.1464410X.2010.09334.x.

[7] Droz J-P, Aapro M, Balducci L, Boyle H, Van den Broeck T, Cathcart P, et al. Management of prostate cancer in older patients: updated recommendations of a working group of the International Society of Geriatric Oncology. Lancet Oncol 2014;15:e404-14. doi:10.1016/S1470-2045(14)70018-X.

[8] Droz J-P, Albrand G, Gillessen S, Hughes S, Mottet N, Oudard S, et al. Management of Prostate Cancer in Elderly Patients: Recommendations of a Task Force of the International Society of Geriatric Oncology. Eur Urol 2017;72:521-31. doi:10.1016/j.eururo.2016.12.025.

[9] Soubeyran P, Bellera C, Goyard J, Heitz D, Cure H, Rousselot H, et al. Screening for vulnerability in older cancer patients: the ONCODAGE Prospective Multicenter Cohort Study. PLoS One 2014;9:e115060. doi:10.1371/journal.pone.0115060.

[10] Droz J-P, Boyle H, Albrand G, Mottet N, Puts M. Role of Geriatric Oncologists in Optimizing Care of Urological Oncology Patients. Eur Urol Focus 2017;3:385-94.

doi:10.1016/j.euf.2017.10.012.

[11] D’Amico A V, Moul JW, Carroll PR, Sun L, Lubeck D, Chen M-H. Surrogate end point for prostate cancer-specific mortality after radical prostatectomy or radiation therapy. J Natl Cancer Inst 2003;95:1376-83.

[12] Oken MM, Creech RH, Tormey DC, Horton J, Davis TE, McFadden ET, et al. Toxicity and response criteria of the Eastern Cooperative Oncology Group. Am J Clin Oncol 1982;5:649-55.

[13] Wedding U, Kodding D, Pientka L, Steinmetz HT, Schmitz S. Physicians' judgement and comprehensive geriatric assessment (CGA) select different patients as fit for chemotherapy. Crit Rev Oncol Hematol 2007;64:1-9. doi:10.1016/j.critrevonc.2007.05.001.

[14] Wildiers $H$, Heeren P, Puts $M$, Topinkova E, Janssen-Heijnen MLG, Extermann M, et al. International Society of Geriatric Oncology consensus on geriatric assessment in older 
patients with cancer. J Clin Oncol 2014;32:2595-603. doi:10.1200/JCO.2013.54.8347.

[15] Kenis C, Heeren P, Decoster L, Van Puyvelde K, Conings G, Cornelis F, et al. A Belgian Survey on Geriatric Assessment in Oncology Focusing on Large-Scale Implementation and Related Barriers and Facilitators. J Nutr Health Aging 2016;20:60-70. doi:10.1007/s12603-015-0538-4.

[16] Decoster L, Van Puyvelde K, Mohile S, Wedding U, Basso U, Colloca G, et al. Screening tools for multidimensional health problems warranting a geriatric assessment in older cancer patients: an update on SIOG recommendationsdagger. Ann Oncol Off J Eur Soc Med Oncol 2015;26:288-300. doi:10.1093/annonc/mdu210.

[17] Mottet N, Bellmunt J BE et al. EAU - ESTRO - ESUR - SIOG Guidelines on Prostate Cancer. Https//UrowebOrg/Guidelines/Prostate Cancer 20182018.

[18] Tsoi KKF, Chan JYC, Hirai HW, Wong SYS, Kwok TCY. Cognitive Tests to Detect Dementia: A Systematic Review and Meta-analysis. JAMA Intern Med 2015;175:1450-8. doi:10.1001/jamainternmed.2015.2152.

[19] Borson S, Scanlan JM, Chen P, Ganguli M. The Mini-Cog as a screen for dementia: validation in a population-based sample. J Am Geriatr Soc 2003;51:1451-4.

[20] Solomon DH. Geriatric assessment: methods for clinical decision making. JAMA 1988;259:2450-2.

[21] Reuben DB, Fishman LK, McNabney M, Wolde-Tsadik G. Looking inside the black box of comprehensive geriatric assessment: a classification system for problems, recommendations, and implementation strategies. J Am Geriatr Soc 1996;44:835-8.

[22] Ellis G, Gardner M, Tsiachristas A, Langhorne P, Burke O, Harwood RH, et al. Comprehensive geriatric assessment for older adults admitted to hospital. Cochrane Database Syst Rev 2017;9:CD006211. doi:10.1002/14651858.CD006211.pub3.

[23] Magnuson A, Allore H, Cohen HJ, Mohile SG, Williams GR, Chapman A, et al. Geriatric assessment with management in cancer care: Current evidence and potential mechanisms for future research. J Geriatr Oncol 2016;7:242-8. doi:10.1016/j.jgo.2016.02.007.

[24] Mohile SG, Velarde C, Hurria A, Magnuson A, Lowenstein L, Pandya C, et al. Geriatric Assessment-Guided Care Processes for Older Adults: A Delphi Consensus of Geriatric Oncology Experts. J Natl Compr Canc Netw 2015;13:1120-30.

[25] Kenis C, Decoster L, Flamaing J, Debruyne PR, De Groof I, Focan C, et al. Adherence to geriatric assessment-based recommendations in older patients with cancer: a multicenter prospective cohort study in Belgium. Ann Oncol Off J Eur Soc Med Oncol 2018;29:1987-94. doi:10.1093/annonc/mdy210.

[26] Puts MTE, Sattar S, Kulik M, MacDonald ME, McWatters K, Lee K, et al. A randomized phase II trial of geriatric assessment and management for older cancer patients. Support Care Cancer Off J Multinatl Assoc Support Care Cancer 2018;26:109-17. doi:10.1007/s00520-017-3820-7.

[27] Schmidt H, Boese S, Lampe K, Jordan K, Fiedler E, Muller-Werdan U, et al. Trans sectoral care of geriatric cancer patients based on comprehensive geriatric assessment and patientreported quality of life - Results of a multicenter study to develop and pilot test a patientcentered interdisciplinary care concept for geriatric on. J Geriatr Oncol 2017;8:262-70. doi:10.1016/j.jgo.2017.04.002.

[28] Magnuson A, Lemelman T, Pandya C, Goodman M, Noel M, Tejani M, et al. Geriatric assessment with management intervention in older adults with cancer: a randomized pilot 
study. Support Care Cancer Off J Multinatl Assoc Support Care Cancer 2018;26:605-13. doi:10.1007/s00520-017-3874-6.

[29] Hurria A, Levit LA, Dale W, Mohile SG, Muss HB, Fehrenbacher L, et al. Improving the Evidence Base for Treating Older Adults With Cancer: American Society of Clinical Oncology Statement. J Clin Oncol 2015;33:3826-33. doi:10.1200/JCO.2015.63.0319.

[30] Kalsi T, Babic-IIlman G, Ross PJ, Maisey NR, Hughes S, Fields P, et al. The impact of comprehensive geriatric assessment interventions on tolerance to chemotherapy in older people. Br J Cancer 2015;112:1435-44. doi:10.1038/bjc.2015.120.

[31] Mohile SG, Epstein RM, Hurria A, Heckler CE, Duberstein P, Canin BE, et al. Improving communication with older patients with cancer using geriatric assessment (GA): A University of Rochester NCl Community Oncology Research Program (NCORP) cluster randomized controlled trial (CRCT). J Clin Oncol 2018;36:LBA10003-LBA10003.

doi:10.1200/JCO.2018.36.18_suppl.LBA10003.

[32] $\mathrm{NCl}$ clinical trials.

Https://ClinicaltrialsGouv/Ct2/Results?Terms=cancer+and+geriatric+assessment\&search 2018.

[33] Ware P, Bartlett SJ, Pare G, Symeonidis I, Tannenbaum C, Bartlett G, et al. Using eHealth Technologies: Interests, Preferences, and Concerns of Older Adults. Interact J Med Res 2017;6:e3. doi:10.2196/ijmr.4447.

[34] Buck H, Pinter A, Poole E, Boehmer J, Foy A, Black S, et al. Evaluating the older adult experience of a web-based, tablet-delivered heart failure self-care program using gerontechnology principles. Geriatr Nurs 2017;38:537-41. doi:10.1016/j.gerinurse.2017.04.001.

[35] Kurahashi AM, Stinson JN, van Wyk M, Luca S, Jamieson T, Weinstein P, et al. The Perceived Ease of Use and Usefulness of Loop: Evaluation and Content Analysis of a Web-Based Clinical Collaboration System. JMIR Hum Factors 2018;5:e2. doi:10.2196/humanfactors.7882.

[36] Jongstra S, Wijsman LW, Cachucho R, Hoevenaar-Blom MP, Mooijaart SP, Richard E. Cognitive Testing in People at Increased Risk of Dementia Using a Smartphone App: The iVitality Proofof-Principle Study. JMIR MHealth UHealth 2017;5:e68. doi:10.2196/mhealth.6939.

[37] Anderson M PA. Tech Adoption Climbs Among Older Adults. Http://WwwPewinternetOrg/2017/05/17/Tech-Adoption-Climbs-among-Older-Adults/ 2017.

[38] Kim BY, Lee J. Smart Devices for Older Adults Managing Chronic Disease: A Scoping Review. JMIR MHealth UHealth 2017;5:e69. doi:10.2196/mhealth.7141.

[39] Guo Y, Albright D. The effectiveness of telehealth on self-management for older adults with a chronic condition: A comprehensive narrative review of the literature. J Telemed Telecare 2018;24:392-403. doi:10.1177/1357633X17706285.

[40] Fallahzadeh R, Ghasemzadeh H, Shahrokni A. Electronic Assessment of Physical Decline in Geriatric Cancer Patients. Curr Oncol Rep 2018;20:26. doi:10.1007/s11912-018-0670-5.

[41] Loh KP, McHugh C, Mohile SG, Mustian K, Flannery M, Klepin H, et al. Using Information Technology in the Assessment and Monitoring of Geriatric Oncology Patients. Curr Oncol Rep 2018;20:25. doi:10.1007/s11912-018-0672-3.

[42] McCleary NJ, Wigler D, Berry D, Sato K, Abrams T, Chan J, et al. Feasibility of computer-based self-administered cancer-specific geriatric assessment in older patients with gastrointestinal 
malignancy. Oncologist 2013;18:64-72. doi:10.1634/theoncologist.2012-0241.

[43] Hurria A, Akiba C, Kim J, Mitani D, Loscalzo M, Katheria V, et al. Reliability, Validity, and Feasibility of a Computer-Based Geriatric Assessment for Older Adults With Cancer. J Oncol Pract 2016;12:e1025-34. doi:10.1200/JOP.2016.013136.

[44] Shahrokni A, Tin A, Downey RJ, Strong V, Mahmoudzadeh S, Boparai MK, et al. Electronic Rapid Fitness Assessment: A Novel Tool for Preoperative Evaluation of the Geriatric Oncology Patient. J Natl Compr Canc Netw 2017;15:172-9.

[45] Ferrat E, Paillaud E, Caillet P, Laurent M, Tournigand C, Lagrange J-L, et al. Performance of Four Frailty Classifications in Older Patients With Cancer: Prospective Elderly Cancer Patients Cohort Study. J Clin Oncol 2017;35:766-77. doi:10.1200/JCO.2016.69.3143.

[46] Mohile SG, Dale W, Somerfield MR, Hurria A. Practical Assessment and Management of Vulnerabilities in Older Patients Receiving Chemotherapy: ASCO Guideline for Geriatric Oncology Summary. J Oncol Pract 2018;14:442-6. doi:10.1200/JOP.18.00180.

[47] University of california eprognosis: electronic tools. Https://EprognosisUcsfEdu/IndexPhp 2018.

[48] Hamdy FC, Donovan JL, Lane JA, Mason M, Metcalfe C, Holding P, et al. 10-Year Outcomes after Monitoring, Surgery, or Radiotherapy for Localized Prostate Cancer. N Engl J Med 2016;375:1415-24. doi:10.1056/NEJMoa1606220.

[49] Donovan JL, Hamdy FC, Lane JA, Mason M, Metcalfe C, Walsh E, et al. Patient-Reported Outcomes after Monitoring, Surgery, or Radiotherapy for Prostate Cancer. N Engl J Med 2016;375:1425-37. doi:10.1056/NEJMoa1606221.

[50] Joniau S, Briganti A, Gontero P, Gandaglia G, Tosco L, Fieuws S, et al. Stratification of high-risk prostate cancer into prognostic categories: a European multi-institutional study. Eur Urol 2015;67:157-64. doi:10.1016/j.eururo.2014.01.020.

[51] Bill-Axelson A, Holmberg L, Garmo H, Rider JR, Taari K, Busch C, et al. Radical prostatectomy or watchful waiting in early prostate cancer. N Engl J Med 2014;370:932-42. doi:10.1056/NEJMoa1311593.

[52] Wilt TJ, Jones KM, Barry MJ, Andriole GL, Culkin D, Wheeler T, et al. Follow-up of Prostatectomy versus Observation for Early Prostate Cancer. N Engl J Med 2017;377:132-42. doi:10.1056/NEJMoa1615869.

[53] Coughlin GD, Yaxley JW, Chambers SK, Occhipinti S, Samaratunga H, Zajdlewicz L, et al. Robotassisted laparoscopic prostatectomy versus open radical retropubic prostatectomy: 24-month outcomes from a randomised controlled study. Lancet Oncol 2018;19:1051-60. doi:10.1016/S1470-2045(18)30357-7.

[54] van der Poel HG, van den Bergh RCN, Briers E, Cornford P, Govorov A, Henry AM, et al. Focal Therapy in Primary Localised Prostate Cancer: The European Association of Urology Position in 2018. Eur Urol 2018;74:84-91. doi:10.1016/j.eururo.2018.01.001.

[55] Azzouzi A-R, Vincendeau S, Barret E, Cicco A, Kleinclauss F, van der Poel HG, et al. Padeliporfin vascular-targeted photodynamic therapy versus active surveillance in men with low-risk prostate cancer (CLIN1001 PCM301): an open-label, phase 3, randomised controlled trial. Lancet Oncol 2017;18:181-91. doi:10.1016/S1470-2045(16)30661-1.

[56] Chen RC, Rumble RB, Loblaw DA, Finelli A, Ehdaie B, Cooperberg MR, et al. Active Surveillance for the Management of Localized Prostate Cancer (Cancer Care Ontario Guideline): American 
Society of Clinical Oncology Clinical Practice Guideline Endorsement. J Clin Oncol 2016;34:2182-90. doi:10.1200/JCO.2015.65.7759.

[57] Dearnaley D, Syndikus I, Mossop H, Khoo V, Birtle A, Bloomfield D, et al. Conventional versus hypofractionated high-dose intensity-modulated radiotherapy for prostate cancer: 5-year outcomes of the randomised, non-inferiority, phase 3 CHHiP trial. Lancet Oncol 2016;17:1047-60. doi:10.1016/S1470-2045(16)30102-4.

[58] Incrocci L, Wortel RC, Alemayehu WG, Aluwini S, Schimmel E, Krol S, et al. Hypofractionated versus conventionally fractionated radiotherapy for patients with localised prostate cancer (HYPRO): final efficacy results from a randomised, multicentre, open-label, phase 3 trial. Lancet Oncol 2016;17:1061-9. doi:10.1016/S1470-2045(16)30070-5.

[59] Arcangeli G, Saracino B, Arcangeli S, Gomellini S, Petrongari MG, Sanguineti G, et al. Moderate Hypofractionation in High-Risk, Organ-Confined Prostate Cancer: Final Results of a Phase III Randomized Trial. J Clin Oncol 2017;35:1891-7. doi:10.1200/JCO.2016.70.4189.

[60] Catton CN, Lukka H, Gu C-S, Martin JM, Supiot S, Chung PWM, et al. Randomized Trial of a Hypofractionated Radiation Regimen for the Treatment of Localized Prostate Cancer. J Clin Oncol 2017;35:1884-90. doi:10.1200/JCO.2016.71.7397.

[61] Lee WR, Dignam JJ, Amin MB, Bruner DW, Low D, Swanson GP, et al. Randomized Phase III Noninferiority Study Comparing Two Radiotherapy Fractionation Schedules in Patients With Low-Risk Prostate Cancer. J Clin Oncol 2016;34:2325-32. doi:10.1200/JCO.2016.67.0448.

[62] Shahid N, Loblaw A, Chung HT, Cheung P, Szumacher E, Danjoux C, et al. Long-term Toxicity and Health-related Quality of Life after Single-fraction High Dose Rate Brachytherapy Boost and Hypofractionated External Beam Radiotherapy for Intermediate-risk Prostate Cancer. Clin Oncol (R Coll Radiol) 2017;29:412-20. doi:10.1016/j.clon.2017.01.042.

[63] Joseph N, Taylor C, O'Hara C, Choudhury A, Elliott T, Logue J, et al. A combined single highdose rate brachytherapy boost with hypofractionated external beam radiotherapy results in a high rate of biochemical disease free survival in localised intermediate and high risk prostate cancer patients. Radiother Oncol 2016;121:299-303. doi:10.1016/j.radonc.2016.09.016.

[64] Morris WJ, Tyldesley S, Rodda S, Halperin R, Pai H, McKenzie M, et al. Androgen Suppression Combined with Elective Nodal and Dose Escalated Radiation Therapy (the ASCENDE-RT Trial): An Analysis of Survival Endpoints for a Randomized Trial Comparing a Low-Dose-Rate Brachytherapy Boost to a Dose-Escalated External Beam Boost f. Int J Radiat Oncol Biol Phys 2017;98:275-85. doi:10.1016/j.ijrobp.2016.11.026.

[65] Rodda S, Tyldesley S, Morris WJ, Keyes M, Halperin R, Pai H, et al. ASCENDE-RT: An Analysis of Treatment-Related Morbidity for a Randomized Trial Comparing a Low-Dose-Rate Brachytherapy Boost with a Dose-Escalated External Beam Boost for High- and IntermediateRisk Prostate Cancer. Int J Radiat Oncol Biol Phys 2017;98:286-95. doi:10.1016/j.ijrobp.2017.01.008.

[66] Rodda S, Morris WJ, Hamm J, Duncan G. ASCENDE-RT: An Analysis of Health-Related Quality of Life for a Randomized Trial Comparing Low-Dose-Rate Brachytherapy Boost With DoseEscalated External Beam Boost for High- and Intermediate-Risk Prostate Cancer. Int J Radiat Oncol Biol Phys 2017;98:581-9. doi:10.1016/j.ijrobp.2017.02.027.

[67] Hoskin P, Rojas A, Ostler P, Hughes R, Alonzi R, Lowe G. Single-dose high-dose-rate brachytherapy compared to two and three fractions for locally advanced prostate cancer. Radiother Oncol 2017;124:56-60. doi:10.1016/j.radonc.2017.06.014. 
[68] Hamstra DA, Mariados N, Sylvester J, Shah D, Karsh L, Hudes R, et al. Continued Benefit to Rectal Separation for Prostate Radiation Therapy: Final Results of a Phase III Trial. Int J Radiat Oncol Biol Phys 2017;97:976-85. doi:10.1016/j.ijrobp.2016.12.024.

[69] Pasquier D, Nickers P, Peiffert D, Maingon P, Pommier P, Lacornerie T, et al. Hypofractionated stereotactic boost in intermediate risk prostate carcinoma: Preliminary results of a multicenter phase II trial (CKNO-PRO). PLoS One 2017;12:e0187794. doi:10.1371/journal.pone.0187794.

[70] Smith MR, Saad F, Chowdhury S, Oudard S, Hadaschik BA, Graff JN, et al. Apalutamide Treatment and Metastasis-free Survival in Prostate Cancer. N Engl J Med 2018;378:1408-18. doi:10.1056/NEJMoa1715546.

[71] Hussain M, Fizazi K, Saad F, Rathenborg P, Shore N, Ferreira U, et al. Enzalutamide in Men with Nonmetastatic, Castration-Resistant Prostate Cancer. N Engl J Med 2018;378:2465-74. doi:10.1056/NEJMoa1800536.

[72] Tombal B, Saad F, Penson D, Hussain M, Sternberg CN, Morlock R, et al. Patient-reported outcomes following enzalutamide or placebo in men with non-metastatic, castration-resistant prostate cancer (PROSPER): a multicentre, randomised, double-blind, phase 3 trial. Lancet Oncol 2019;20:556-69. doi:10.1016/S1470-2045(18)30898-2.

[73] Graff JN, Baciarello G, Armstrong AJ, Higano CS, Iversen P, Flaig TW, et al. Efficacy and safety of enzalutamide in patients 75 years or older with chemotherapy-naive metastatic castrationresistant prostate cancer: results from PREVAIL. Ann Oncol Off J Eur Soc Med Oncol 2016;27:286-94. doi:10.1093/annonc/mdv542.

[74] Fizazi K, Shore N, Tammela TL, Ulys A, Vjaters E, Polyakov S, et al. Darolutamide in Nonmetastatic, Castration-Resistant Prostate Cancer. N Engl J Med 2019;380:1235-46. doi:10.1056/NEJMoa1815671.

[75] Fizazi K, Tran N, Fein L, Matsubara N, Rodriguez-Antolin A, Alekseev BY, et al. Abiraterone plus Prednisone in Metastatic, Castration-Sensitive Prostate Cancer. N Engl J Med 2017;377:35260. doi:10.1056/NEJMoa1704174.

[76] Chi KN, Protheroe A, Rodriguez-Antolin A, Facchini G, Suttman H, Matsubara N, et al. Patientreported outcomes following abiraterone acetate plus prednisone added to androgen deprivation therapy in patients with newly diagnosed metastatic castration-naive prostate cancer (LATITUDE): an international, randomised phase 3 trial. Lancet Oncol 2018;19:194206. doi:10.1016/S1470-2045(17)30911-7.

[77] James ND, de Bono JS, Spears MR, Clarke NW, Mason MD, Dearnaley DP, et al. Abiraterone for Prostate Cancer Not Previously Treated with Hormone Therapy. N Engl J Med 2017;377:338-51. doi:10.1056/NEJMoa1702900.

[78] Rydzewska LHM, Burdett S, Vale CL, Clarke NW, Fizazi K, Kheoh T, et al. Adding abiraterone to androgen deprivation therapy in men with metastatic hormone-sensitive prostate cancer: $\mathrm{A}$ systematic review and meta-analysis. Eur J Cancer 2017;84:88-101. doi:10.1016/j.ejca.2017.07.003.

[79] Parker CC, James ND, Brawley CD, Clarke NW, Hoyle AP, Ali A, et al. Radiotherapy to the primary tumour for newly diagnosed, metastatic prostate cancer (STAMPEDE): a randomised controlled phase 3 trial. Lancet (London, England) 2018;392:2353-66. doi:10.1016/S01406736(18)32486-3.

[80] Kyriakopoulos CE, Chen Y-H, Carducci MA, Liu G, Jarrard DF, Hahn NM, et al. Chemohormonal 
Therapy in Metastatic Hormone-Sensitive Prostate Cancer: Long-Term Survival Analysis of the Randomized Phase III E3805 CHAARTED Trial. J Clin Oncol 2018;36:1080-7.

doi:10.1200/JCO.2017.75.3657.

[81] Gravis G, Boher J-M, Joly F, Soulie M, Albiges L, Priou F, et al. Androgen Deprivation Therapy (ADT) Plus Docetaxel Versus ADT Alone in Metastatic Non castrate Prostate Cancer: Impact of Metastatic Burden and Long-term Survival Analysis of the Randomized Phase 3 GETUG-AFU15 Trial. Eur Urol 2016;70:256-62. doi:10.1016/j.eururo.2015.11.005.

[82] James ND, Sydes MR, Clarke NW, Mason MD, Dearnaley DP, Spears MR, et al. Addition of docetaxel, zoledronic acid, or both to first-line long-term hormone therapy in prostate cancer (STAMPEDE): survival results from an adaptive, multiarm, multistage, platform randomised controlled trial. Lancet (London, England) 2016;387:1163-77. doi:10.1016/S01406736(15)01037-5.

[83] Gravis G, Boher J-M, Chen Y-H, Liu G, Fizazi K, Carducci MA, et al. Burden of Metastatic Castrate Naive Prostate Cancer Patients, to Identify Men More Likely to Benefit from Early Docetaxel: Further Analyses of CHAARTED and GETUG-AFU15 Studies. Eur Urol 2018;73:84755. doi:10.1016/j.eururo.2018.02.001.

[84] Sweeney CJ, Chen Y-H, Carducci M, Liu G, Jarrard DF, Eisenberger M, et al. Chemohormonal Therapy in Metastatic Hormone-Sensitive Prostate Cancer. N Engl J Med 2015;373:737-46. doi:10.1056/NEJMoa1503747.

[85] Tsao C-K, Oh WK. First-Line Treatment of Hormone-Sensitive Metastatic Prostate Cancer: Is There a Single Standard of Care? J Clin Oncol 2018;36:1060-1. doi:10.1200/JCO.2017.77.4315.

[86] Lavaud P, Gravis G, Foulon S, Joly F, Oudard S, Priou F, et al. Anticancer Activity and Tolerance of Treatments Received Beyond Progression in Men Treated Upfront with Androgen Deprivation Therapy With or Without Docetaxel for Metastatic Castration-naive Prostate Cancer in the GETUG-AFU 15 Phase 3 Trial. Eur Urol 2018;73:696-703. doi:10.1016/j.eururo.2017.09.022.

[87] Morris MJ, Rumble RB, Basch E, Hotte SJ, Loblaw A, Rathkopf D, et al. Optimizing Anticancer Therapy in Metastatic Non-Castrate Prostate Cancer: American Society of Clinical Oncology Clinical Practice Guideline. J Clin Oncol 2018;36:1521-39. doi:10.1200/JCO.2018.78.0619.

[88] Sydes MR, Spears MR, Mason MD, Clarke NW, Dearnaley DP, de Bono JS, et al. Adding abiraterone or docetaxel to long-term hormone therapy for prostate cancer: directly randomised data from the STAMPEDE multi-arm, multi-stage platform protocol. Ann Oncol Off J Eur Soc Med Oncol 2018;29:1235-48. doi:10.1093/annonc/mdy072.

[89] Wallis CJD, Klaassen Z, Bhindi B, Goldberg H, Chandrasekar T, Farrell AM, et al. Comparison of Abiraterone Acetate and Docetaxel with Androgen Deprivation Therapy in High-risk and Metastatic Hormone-naive Prostate Cancer: A Systematic Review and Network Meta-analysis. Eur Urol 2018;73:834-44. doi:10.1016/j.eururo.2017.10.002.

[90] Gravis G, Fizazi K, Joly F, Oudard S, Priou F, Esterni B, et al. Androgen-deprivation therapy alone or with docetaxel in non-castrate metastatic prostate cancer (GETUG-AFU 15): a randomised, open-label, phase 3 trial. Lancet Oncol 2013;14:149-58. doi:10.1016/S14702045(12)70560-0.

[91] Horgan AM, Seruga B, Pond GR, Alibhai SM, Amir E, De Wit R, et al. Tolerability and efficacy of docetaxel in older men with metastatic castrate-resistant prostate cancer (mCRPC) in the TAX 327 trial. J Geriatr Oncol 2014;5:119-26. doi:10.1016/j.jgo.2013.12.001. 
[92] Italiano A, Ortholan C, Oudard S, Pouessel D, Gravis G, Beuzeboc P, et al. Docetaxel-based chemotherapy in elderly patients (age 75 and older) with castration-resistant prostate cancer. Eur Urol 2009;55:1368-75. doi:10.1016/j.eururo.2008.07.078.

[93] Oudard S, Fizazi K, Sengelov L, Daugaard G, Saad F, Hansen S, et al. Cabazitaxel Versus Docetaxel As First-Line Therapy for Patients With Metastatic Castration-Resistant Prostate Cancer: A Randomized Phase III Trial-FIRSTANA. J Clin Oncol 2017;35:3189-97. doi:10.1200/JCO.2016.72.1068.

[94] Eisenberger M, Hardy-Bessard A-C, Kim CS, Geczi L, Ford D, Mourey L, et al. Phase III Study Comparing a Reduced Dose of Cabazitaxel $(20 \mathrm{mg} / \mathrm{m}(2))$ and the Currently Approved Dose (25 $\mathrm{mg} / \mathrm{m}(2))$ in Postdocetaxel Patients With Metastatic Castration-Resistant Prostate CancerPROSELICA. J Clin Oncol 2017;35:3198-206. doi:10.1200/JCO.2016.72.1076.

[95] Climent MA, Perez-Valderrama B, Mellado B, Fernandez Parra EM, Fernandez Calvo O, Ochoa de Olza $\mathrm{M}$, et al. Weekly cabazitaxel plus prednisone is effective and less toxic for "unfit" metastatic castration-resistant prostate cancer: Phase II Spanish Oncology Genitourinary Group (SOGUG) trial. Eur J Cancer 2017;87:30-7. doi:10.1016/j.ejca.2017.09.028.

[96] Clement-Zhao A, Auvray M, Aboudagga H, Blanc-Durand F, Angelergues A, Vano YA, et al. Safety and efficacy of 2-weekly cabazitaxel in metastatic castration-resistant prostate cancer. BJU Int 2018;121:203-8. doi:10.1111/bju.13855.

[97] Scher HI, Heller G, Molina A, Attard G, Danila DC, Jia X, et al. Circulating tumor cell biomarker panel as an individual-level surrogate for survival in metastatic castration-resistant prostate cancer. J Clin Oncol 2015;33:1348-55. doi:10.1200/JCO.2014.55.3487.

[98] Robinson D, Van Allen EM, Wu Y-M, Schultz N, Lonigro RJ, Mosquera J-M, et al. Integrative clinical genomics of advanced prostate cancer. Cell 2015;161:1215-28. doi:10.1016/j.cell.2015.05.001.

[99] Mateo J, Carreira S, Sandhu S, Miranda S, Mossop H, Perez-Lopez R, et al. DNA-Repair Defects and Olaparib in Metastatic Prostate Cancer. N Engl J Med 2015;373:1697-708. doi:10.1056/NEJMoa1506859.

[100] Hussain M, Daignault-Newton S, Twardowski PW, Albany C, Stein MN, Kunju LP, et al. Targeting Androgen Receptor and DNA Repair in Metastatic Castration-Resistant Prostate Cancer: Results From NCl 9012. J Clin Oncol 2018;36:991-9. doi:10.1200/JCO.2017.75.7310.

[101] Clarke N, Wiechno P, Alekseev B, Sala N, Jones R, Kocak I, et al. Olaparib combined with abiraterone in patients with metastatic castration-resistant prostate cancer: a randomised, double-blind, placebo-controlled, phase 2 trial. Lancet Oncol 2018;19:975-86. doi:10.1016/S1470-2045(18)30365-6.

[102] Beer TM, Kwon ED, Drake CG, Fizazi K, Logothetis C, Gravis G, et al. Randomized, DoubleBlind, Phase III Trial of Ipilimumab Versus Placebo in Asymptomatic or Minimally Symptomatic Patients With Metastatic Chemotherapy-Naive Castration-Resistant Prostate Cancer. J Clin Oncol 2017;35:40-7. doi:10.1200/JCO.2016.69.1584.

[103] Kwon ED, Drake CG, Scher HI, Fizazi K, Bossi A, van den Eertwegh AJM, et al. Ipilimumab versus placebo after radiotherapy in patients with metastatic castration-resistant prostate cancer that had progressed after docetaxel chemotherapy (CA184-043): a multicentre, randomised, double-blind, phase 3 trial. Lancet Oncol 2014;15:700-12. doi:10.1016/S14702045(14)70189-5.

[104] Graff JN, Alumkal JJ, Drake CG, Thomas G V, Redmond WL, Farhad M, et al. Early evidence of 
anti-PD-1 activity in enzalutamide-resistant prostate cancer. Oncotarget 2016;7:52810-7. doi:10.18632/oncotarget.10547.

[105] De Bono JS, Goh JCH, Ojamaa K, Piulats Rodriguez JM, Drake CG, Hoimes CJ, et al. KEYNOTE199: Pembrolizumab (pembro) for docetaxel-refractory metastatic castration-resistant prostate cancer (mCRPC). J Clin Oncol 2018;36:5007. doi:10.1200/JCO.2018.36.15_suppl.5007.

[106] Lalani A-KA, Bosse D, McGregor BA, Choueiri TK. Immunotherapy in the Elderly. Eur Urol Focus 2017;3:403-12. doi:10.1016/j.euf.2017.11.008.

[107] Rogiers A, van den Oord JJ, Garmyn M, Stas M, Kenis C, Wildiers H, et al. Novel Therapies for Metastatic Melanoma: An Update on Their Use in Older Patients. Drugs Aging 2015;32:82134. doi:10.1007/s40266-015-0304-7.

[108] Prior JO, Gillessen S, Wirth M, Dale W, Aapro M, Oyen WJG. Radiopharmaceuticals in the elderly cancer patient: Practical considerations, with a focus on prostate cancer therapy: A position paper from the International Society of Geriatric Oncology Task Force. Eur J Cancer 2017;77:127-39. doi:10.1016/j.ejca.2017.01.030.

[109] Parker C, Zhan L, Cislo P, Reuning-Scherer J, Vogelzang NJ, Nilsson S, et al. Effect of radium223 dichloride ( $\mathrm{Ra}-223$ ) on hospitalisation: An analysis from the phase 3 randomised Alpharadin in Symptomatic Prostate Cancer Patients (ALSYMPCA) trial. Eur J Cancer 2017;71:1-6. doi:10.1016/j.ejca.2016.10.020.

[110] Vogelzang NJ, Coleman RE, Michalski JM, Nilsson S, O'Sullivan JM, Parker C, et al. Hematologic Safety of Radium-223 Dichloride: Baseline Prognostic Factors Associated With Myelosuppression in the ALSYMPCA Trial. Clin Genitourin Cancer 2017;15:42-52.e8. doi:10.1016/j.clgc.2016.07.027.

[111] Dan TD, Eldredge-Hindy HB, Hoffman-Censits J, Lin J, Kelly WK, Gomella LG, et al. Hematologic Toxicity of Concurrent Administration of Radium-223 and Next-generation Antiandrogen Therapies. Am J Clin Oncol 2017;40:342-7. doi:10.1097/COC.0000000000000181.

[112] EMA press release abiraterone - radium. Http//WwwEmaEuropaEu/Doc/En GB/Document Libr - Prod Information/Human/002653/WC500156172Pdf 2018.

[113] Brauer A, Grubert LS, Roll W, Schrader AJ, Schafers M, Bogemann M, et al. (177)Lu-PSMA-617 radioligand therapy and outcome in patients with metastasized castration-resistant prostate cancer. Eur J Nucl Med Mol Imaging 2017;44:1663-70. doi:10.1007/s00259-017-3751-z.

[114] Rhee H, Gunter JH, Heathcote P, Ho K, Stricker P, Corcoran NM, et al. Adverse effects of androgen-deprivation therapy in prostate cancer and their management. BJU Int 2015;115 Suppl:3-13. doi:10.1111/bju.12964.

[115] Mohile SG, Mustian K, Bylow K, Hall W, Dale W. Management of complications of androgen deprivation therapy in the older man. Crit Rev Oncol Hematol 2009;70:235-55. doi:10.1016/j.critrevonc.2008.09.004.

[116] Ahmadi H, Daneshmand S. Androgen deprivation therapy: evidence-based management of side effects. BJU Int 2013;111:543-8. doi:10.1111/j.1464-410X.2012.11774.x.

[117] Sun M, Cole AP, Hanna N, Mucci LA, Berry DL, Basaria S, et al. Cognitive Impairment in Men with Prostate Cancer Treated with Androgen Deprivation Therapy: A Systematic Review and Meta-Analysis. J Urol 2018;199:1417-25. doi:10.1016/j.juro.2017.11.136.

[118] Alibhai SMH, Zukotynski K, Walker-Dilks C, Emmenegger U, Finelli A, Morgan SC, et al. Bone 
Health and Bone-Targeted Therapies for Nonmetastatic Prostate Cancer: A Systematic Review and Meta-analysis. Ann Intern Med 2017;167:341-50. doi:10.7326/M16-2577.

[119] Campos C, Sotomayor P, Jerez D, Gonzalez J, Schmidt CB, Schmidt K, et al. Exercise and prostate cancer: From basic science to clinical applications. Prostate 2018;78:639-45. doi:10.1002/pros.23502.

[120] Alibhai SMH, Santa Mina D, Ritvo P, Sabiston C, Krahn M, Tomlinson G, et al. A phase II RCT and economic analysis of three exercise delivery methods in men with prostate cancer on androgen deprivation therapy. BMC Cancer 2015;15:312. doi:10.1186/s12885-015-1316-8.

[121] Hurria A, Togawa K, Mohile SG, Owusu C, Klepin HD, Gross CP, et al. Predicting chemotherapy toxicity in older adults with cancer: a prospective multicenter study. J Clin Oncol 2011;29:3457-65. doi:10.1200/JCO.2011.34.7625.

[122] Extermann M, Boler I, Reich RR, Lyman GH, Brown RH, DeFelice J, et al. Predicting the risk of chemotherapy toxicity in older patients: the Chemotherapy Risk Assessment Scale for HighAge Patients (CRASH) score. Cancer 2012;118:3377-86. doi:10.1002/cncr.26646.

[123] Smith TJ, Bohlke K, Lyman GH, Carson KR, Crawford J, Cross SJ, et al. Recommendations for the Use of WBC Growth Factors: American Society of Clinical Oncology Clinical Practice Guideline Update. J Clin Oncol 2015;33:3199-212. doi:10.1200/JCO.2015.62.3488.

[124] Tsao C-K, Galsky MD, Oh WK. Docetaxel for Metastatic Hormone-sensitive Prostate Cancer: Urgent Need to Minimize the Risk of Neutropenic Fever. Eur Urol 2016;70:707-8. doi:10.1016/j.eururo.2016.06.041.

[125] Fizazi K, Scher HI, Molina A, Logothetis CJ, Chi KN, Jones RJ, et al. Abiraterone acetate for treatment of metastatic castration-resistant prostate cancer: final overall survival analysis of the COU-AA-301 randomised, double-blind, placebo-controlled phase 3 study. Lancet Oncol 2012;13:983-92. doi:10.1016/S1470-2045(12)70379-0.

[126] Scher HI, Fizazi K, Saad F, Taplin M-E, Sternberg CN, Miller K, et al. Increased survival with enzalutamide in prostate cancer after chemotherapy. N Engl J Med 2012;367:1187-97. doi:10.1056/NEJMoa1207506.

[127] Del Re M, Fogli S, Derosa L, Massari F, De Souza P, Crucitta S, et al. The role of drug-drug interactions in prostate cancer treatment: Focus on abiraterone acetate/prednisone and enzalutamide. Cancer Treat Rev 2017;55:71-82. doi:10.1016/j.ctrv.2017.03.001.

[128] Droz JP, Angenieux O AG. Geriatric Oncology in Tropical and Developing Countries. Geriatr. Oncol., 2017.

[129] NCCN Harmonized Guidelines ${ }^{\mathrm{TM}}$ for Sub-Saharan Africao Title. Ttps://WwwNccnOrg/Harmonized/ 2018.

[130] Gillessen S, Attard G, Beer TM, Beltran H, Bossi A, Bristow R, et al. Management of Patients with Advanced Prostate Cancer: The Report of the Advanced Prostate Cancer Consensus Conference APCCC 2017. Eur Urol 2018;73:178-211. doi:10.1016/j.eururo.2017.06.002. 


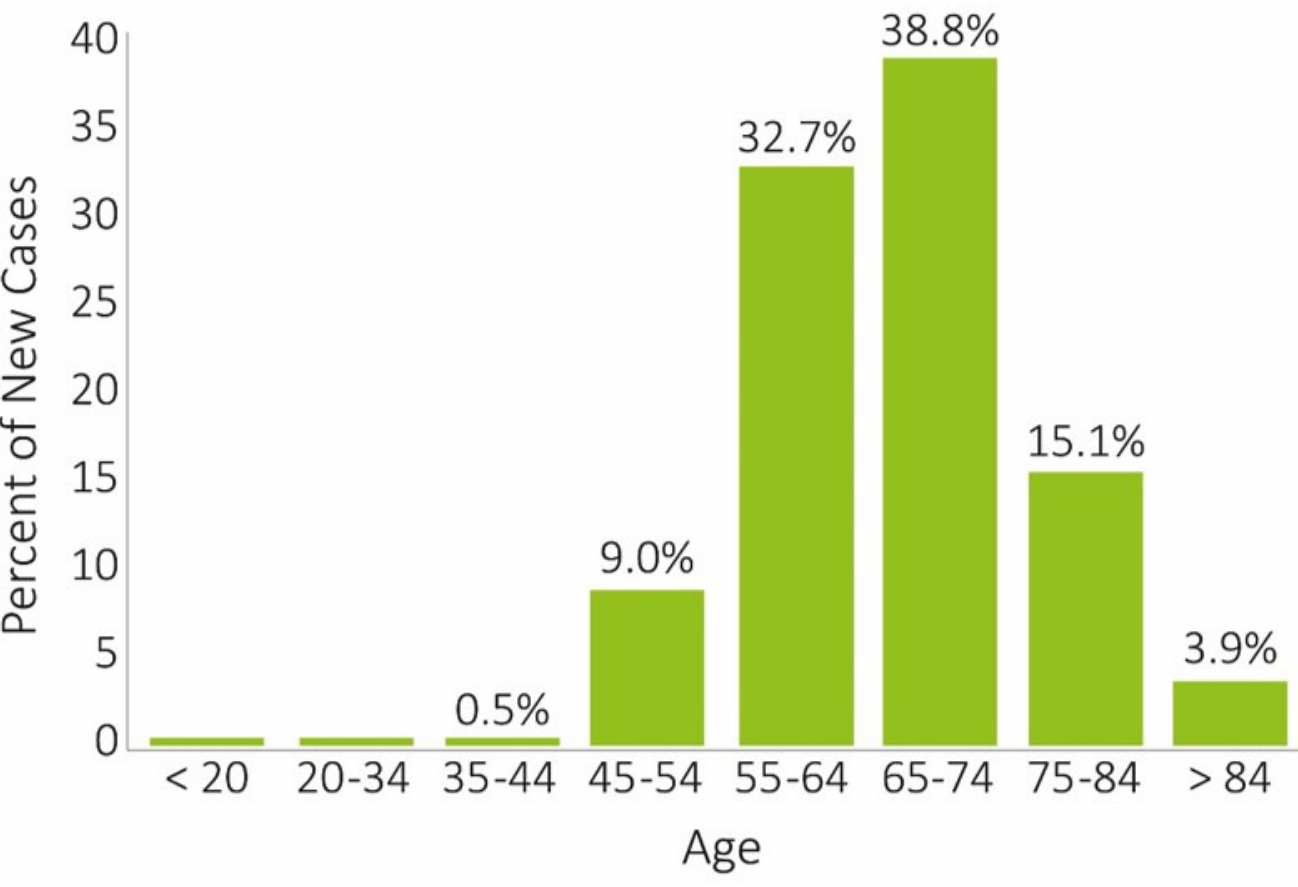

Median age at diagnosis: 66 years 


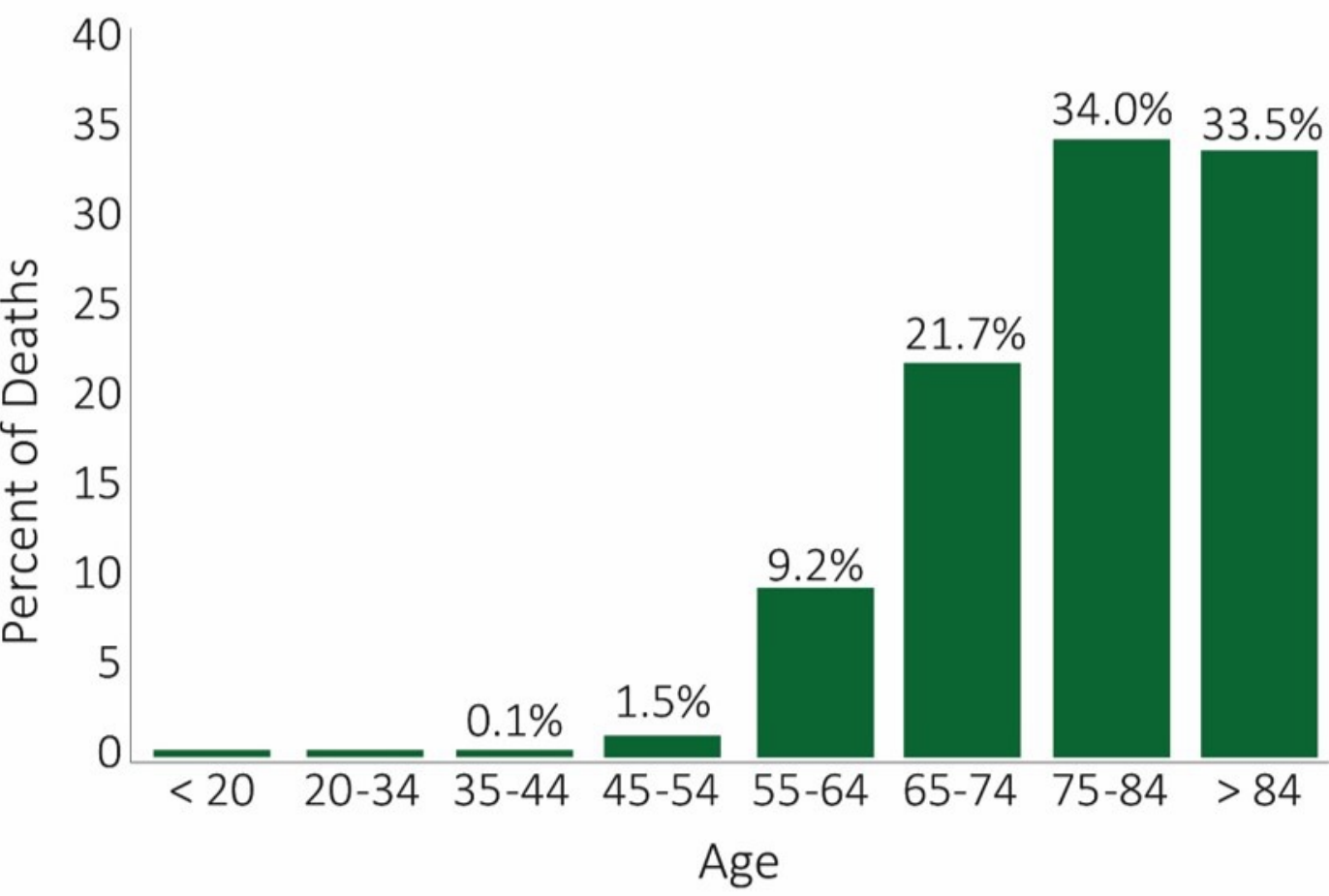

Median age at death: 80 years 


\section{Screening by $\mathrm{G} 8$ and mini-COG ${ }^{\mathrm{TM}}$ *}

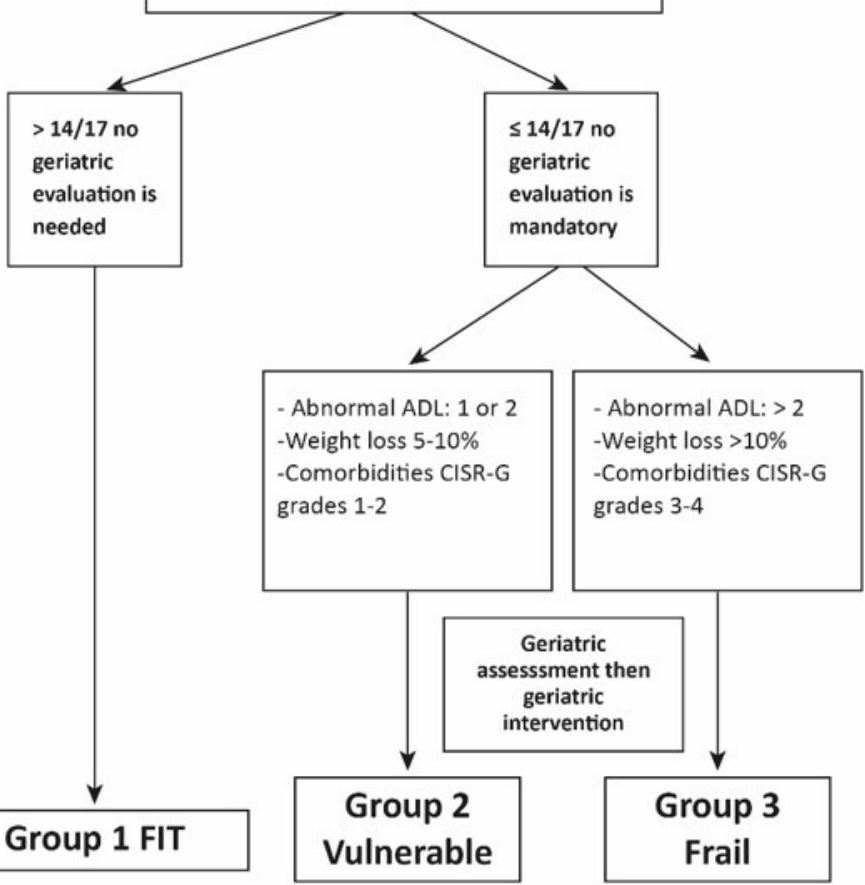




\section{Health status evaluation}

Treatment should be based on health status rather than age, and also on patient preference. (Unchanged)

$>$ The taskforce recommends the screening of frailty using the $\mathrm{G} 8$ tool and of cognitive impairment through the mini-COG ${ }^{\mathrm{TM}}$. Patients with mini-COG ${ }^{\mathrm{TM}} \leq 3 / 5$ require a more detailed cognitive evaluation. (Unchanged)

$>$ In patients with G8 $\leq 14 / 17$, evaluation of dependence, comorbidities and nutritional status are the first steps in assigning patients to one of three health status groups: 1 ) "healthy" or "fit" patients; 2) "vulnerable" patients; and 3) "frail" patients. Vulnerable and frail patients are candidate for geriatric assessment and geriatric interventions. (New)

$>$ Patients benefit most from a geriatric assessment when vulnerability / frailty is detected since geriatric management will allow a more appropriate treatment plan.(Modified)

\section{Management of localized prostate cancer in older patients}

Drostate cancer risk should be based on the D'Amico classification (Unchanged)

$>$ Fit older patients with a chance of living $>10$ years with prostate cancer in the D'Amico high-risk group are most likely to benefit from treatment with curative intent. (Unchanged)

$>$ Older patients with prostate cancer at D'Amico low- to intermediate-risk are likely to benefit from active surveillance or watchful waiting, based on their individual expected survival. A curative approach must be discussed with intermediate risk patients who have at least 10 years' life expectancy. (Modified)

$>$ The balance of benefits and harms of ADT for localized prostate cancer should be carefully assessed. Note the increased risk of diabetes, cardiovascular complications, osteoporosis, bone fractures and cognitive dysfunction. Adjuvant ADT should only be used in intermediate and particularly high risk disease. With patients who are either symptomatic or asymptomatic but at D'Amico high-risk, discuss ADT monotherapy only with those unwilling or unable to receive any form of local treatment. (Modified)

$>$ A validated tool such as the Schonberg or Lee Index can aid in predicting life expectancy independent of prostate cancer. (New)

\section{Management of advanced prostate cancer in older patients}

Metastatic castration sensitive prostate cancer (mCSPC)

- ADT plus 6 cycles docetaxel is a recommended first-line treatment in fit men with newly diagnosed hormone-sensitive metastatic prostate cancer. It is only appropriate in the setting of high volume disease. Use of primary prophylaxis with G-CSF should be considered. (New)

- ADT plus abiraterone is the other recommended first-line treatment. It is indicated in fit men with newly diagnosed hormone-sensitive metastatic prostate cancer in the setting of high risk disease. Abiraterone use in the M1 indication should be carefully balanced against potential side effects and costs. (New)

- In all other cases, ADT alone remains the standard. (Unchanged)

- Patients treated with ADT should have their bone mineral density evaluated and should receive calcium (if dietary intake is insufficient) and vitamin $D$ supplementation. In those at high risk of low-trauma/fragility fracture, use of 
denosumab $60 \mathrm{mg}$ subcutaneous injection every 6 months in osteoporosis prevention/treatment-approved doses is recommended. In settings where denosumab is not available, bisphosphonates in osteoporosis prevention/treatment-approved doses should be considered. Fracture risk is best assessed using a validated calculator. (Modified)

- Prostate radiotherapy should be a standard treatment option for fit men with newly diagnosed disease with a low metastatic burden (New)

\section{Metastatic castration resistant prostate cancer (mCRPC)}

- In mCRPC, docetaxel $75 \mathrm{mg} / \mathrm{m}^{2}$ every 3 weeks is suitable for fit older patients. For vulnerable older patients, treatment should be guided by the results of a geriatric assessment and intervention, while the biweekly regimen should be considered in those who are unable to receive the three-weekly regimen. Use of primary prophylaxis with G-CSF should be considered with the three-weekly regimen. (New)

- In MCRPC, abiraterone and enzalutamide are suitable first-line options. (Modified)

- In patients who have received docetaxel, options include cabazitaxel $\left(20 \mathrm{mg} / \mathrm{m}^{2}\right)$, abiraterone and enzalutamide. (Modified)

- The optimum sequencing of therapies is subject to research. After failure of a novel endocrine agent, agents with another mechanism of action including taxanes or radium-223 (though only in cases of bone metastases) should be the preferred option due to cross-resistance between androgen receptor-targeted agents. (New)

- Careful evaluation of drug-drug interactions and proactive management of adverse events is needed in older patients. It is important to perform an initial cardiac evaluation, to treat pre-existing high blood pressure, to correct hypokalaemia, to monitor CBC, ASAT/ALAT, kalemia, glycaemia and blood pressure. Prospective evaluation of side effects of new hormone treatment should be studied in routine clinical practice. (New)

- Patients with bone metastases with no visceral or bulky lymph node metastases receiving first-line treatment, and after failure to docetaxel, are eligible for radium-223 (Modified)

- Palliative treatments include radiotherapy, radiopharmaceuticals, bone-targeted therapies, palliative surgery, and medical treatments for pain and other symptoms. (Unchanged)

$>$ Early palliation should be implemented (principally in mCRPC). (Unchanged)

$>$ Adapted Physical Activity is advocated at all stages of prostate cancer management; further clinical research in older patients is recommended. (New)

$>$ The management of the patient and family should include a multidisciplinary approach involving urologist, medical oncologist, radiation oncologist, geriatrician, primary care physician, nurse and palliative medicine specialist. (Modified)

$>$ Developing guidelines applicable in developing countries is a challenge for the future (New) 
Table 2: G8 screening tool ${ }^{9}$

\begin{tabular}{|c|c|c|}
\hline \multirow{3}{*}{$\begin{array}{l}\text { A - Has food intake } \\
\text { declined over the past } 3 \\
\text { months due to loss of } \\
\text { appetite, digestive } \\
\text { problems, chewing, or } \\
\text { swallowing difficulties? }\end{array}$} & Severe decrease in food intake & 0 \\
\hline & Moderate decrease in food intake & 1 \\
\hline & No decrease in food intake & 2 \\
\hline \multirow{4}{*}{$\begin{array}{l}\text { B - Weight loss during } \\
\text { the last } 3 \text { months? }\end{array}$} & Weight loss $>3 \mathrm{~kg}$ & 0 \\
\hline & Does not know & 1 \\
\hline & Weight loss $1-3 \mathrm{~kg}$ & 2 \\
\hline & No weight loss & 3 \\
\hline \multirow[t]{3}{*}{ C - Mobility } & Bed or chair bound & 0 \\
\hline & Able to get out of bed/chair but does not go out & 1 \\
\hline & Goes out & 2 \\
\hline \multirow{3}{*}{$\begin{array}{l}\text { D - Neuropsychological } \\
\text { problems? }\end{array}$} & Severe depression or dementia & 0 \\
\hline & Mild dementia & 1 \\
\hline & No psychological problems & 2 \\
\hline \multirow{4}{*}{$\begin{array}{l}\text { E - BMI (Body Mass } \\
\text { Index)? (weight in } \\
\mathrm{kg}) /(\text { height in } \mathrm{m} \text { ) }\end{array}$} & $\mathrm{BMI}<19$ & 0 \\
\hline & BMI 19 to $<21$ & 1 \\
\hline & BMI 21 to $<23$ & 2 \\
\hline & $\mathrm{BMI} \geq 23$ & 3 \\
\hline \multirow{2}{*}{$\begin{array}{l}\mathrm{F}-\text { Takes more than } 3 \\
\text { prescription drugs per } \\
\text { day? }\end{array}$} & Yes & 0 \\
\hline & No & 1 \\
\hline \multirow{4}{*}{$\begin{array}{l}\mathrm{G} \text { - In comparison with } \\
\text { other people of the same } \\
\text { age, how does the patient } \\
\text { consider his/her health } \\
\text { status? }\end{array}$} & Not as good & 0 \\
\hline & Does not know & 0.5 \\
\hline & As good & 1 \\
\hline & Better & 2 \\
\hline \multirow[t]{3}{*}{ H- Age } & $\geq 86$ & 0 \\
\hline & $80-85$ & 1 \\
\hline & $<80$ & 2 \\
\hline
\end{tabular}


Table 3: mini-COG ${ }^{\mathrm{TM}}$ cognitive screening too ${ }^{19}$. Copyright S. Borson. With permission of the author (soob@uw.edu)

$\underline{\text { Step } 1: \text { three words registation }}$

Look directly at person and say, "Please listen carefully. I am going to say three words that I want you to repeat back to me now and try to remember. The words are [select a list of words from the versions below]. Please say them for me now." If the person is unable to repeat the words after three attempts, move on to Step 2 (clock drawing). The following and other word lists have been used in one or more clinical studies. For repeated administrations, use of an alternative word list is recommended.

\begin{tabular}{|l|l|l|l|l|l|}
\hline Version 1 & Version 2 & Version 3 & Version 4 & Version 5 & Version 6 \\
Banana & Leader & Village & River & Captain & Daughter \\
Sunrise & Season & Kitchen & Nation & Garden & Heaven \\
Chair & Table & Baby & Finger & Picture & Mountain \\
\hline
\end{tabular}

Step 2: clock drawing

Say: "Next, I want you to draw a clock for me. First, put in all of the numbers where they go." When that is completed, say: "Now, set the hands to 10 past 11." Use preprinted circle (see next page) for this exercise. Repeat instructions as needed as this is not a memory test. Move to Step 3 if the clock is not complete within three minutes.

Step 3: three words recall

Ask the person to recall the three words you stated in Step 1. Say: "What were the three words I asked you to remember?" Record the word list version number and the person's answers.

Scoring

- Word Recall: (0-3 points)

$=1$ point for each word spontaneously recalled without cueing.

- Clock Draw: (0 or 2 points)

$=$ Normal clock: 2 points. A normal clock has all numbers placed in the correct sequence and approximately correct position (e.g., 12, 3, 6 and 9 are in anchor positions) with no missing or duplicate numbers. Hands are pointing to the 11 and 2 (11:10). Hand length is not scored.

Inability or refusal to draw a clock (abnormal) $=0$ points.

- Total Score: (0-5 points)

$=$ Total score: Word Recall score + Clock Draw score.

A cut point of $\leq 3$ on the Mini-COG ${ }^{\mathrm{TM}}$ has been validated for dementia screening, but many individuals with clinically meaningful cognitive impairment will score higher. When greater sensitivity is desired, a cut point of $<4$ is recommended as it may indicate a need for further evaluation of cognitive status. 
Table 4: Randomized trials in mCSPC including older patients.

\begin{tabular}{|c|c|c|c|c|}
\hline Protocol & CHAARTED 82 & $\begin{array}{l}\text { STAMPEDE } \\
\text { docetaxe }{ }^{80} \\
\end{array}$ & LATITUDE $^{73}$ & $\begin{array}{l}\text { STAMPEDE } \\
\text { Abiraterone }^{75} \\
\end{array}$ \\
\hline Comparison & $\begin{array}{l}\text { ADT+ docetaxel ( } 6 \\
\text { cycles) vs ADT }\end{array}$ & $\begin{array}{l}\text { ADT+ docetaxel ( } 6 \\
\text { cycles) vs ADT }\end{array}$ & $\begin{array}{l}\text { ADT+ Abiraterone vs } \\
\text { ADT }\end{array}$ & $\begin{array}{l}\text { ADT+ Abiraterone vs } \\
\text { ADT }\end{array}$ \\
\hline Selection criteria & $\begin{array}{l}\text { M1: } 100 \% \\
\text { No previous } \\
\text { treatment: } 73 \% \\
\text { High (65\%) and low } \\
\text { volume (35\%) } \\
\text { disease } \\
\text { High volume } \\
\text { defined as } \geq 4 \text { bone } \\
\text { metastases with at } \\
\text { least one beyond } \\
\text { the spine or pelvis } \\
\text { and/or visceral } \\
\text { metastases }\end{array}$ & $\begin{array}{l}\text { Newly diagnosed } \\
\text { M1 (59\%), N+ or high- } \\
\text { risk locally } \\
\text { advanced ( } \geq 2 \\
\text { features: T3/4, } \\
\text { Gleason score of } \\
\text { 8-10, and PSA } \geq 40 \\
\mathrm{ng} / \mathrm{mL} \text { ); } \\
\text { or } \\
\text { previously treated } \\
\text { with radical surgery, } \\
\text { radiotherapy, or } \\
\text { both and relapsing } \\
\text { with high-risk } \\
\text { features. }\end{array}$ & $\begin{array}{l}\text { M1: } 100 \% \\
\text { Newly diagnosed } \\
\text { High risk } \geq 2 \text { of the } \\
\text { following features: } \\
\text { Gleason score } \geq 8, \\
\text { more than } 3 \text { bone } \\
\text { metastases on the } \\
\text { bone scan, presence } \\
\text { of measurable } \\
\text { visceral disease }\end{array}$ & $\begin{array}{l}\text { Newly diagnosed } \\
\mathrm{M} 1 \text { (49\%), N+ or high- } \\
\text { risk locally } \\
\text { advanced ( } \geq 2 \text { features: } \\
\mathrm{T} 3 / 4, \text { Gleason score of } \\
\text { 8-10, and PSA } \geq 40 \\
\mathrm{ng} / \mathrm{mL} \text { ); or } \\
\text { previously treated with } \\
\text { radical surgery, } \\
\text { radiotherapy, or } \\
\text { both and relapsing with } \\
\text { high-risk features. }\end{array}$ \\
\hline $\begin{array}{l}\text { Median age } \\
\text { (range) } \\
\% \text { aged } \geq 70 \\
\% \text { aged } \geq 75\end{array}$ & $\begin{array}{l}64 \text { years } \\
(36-91) \\
22 \% \\
\text { NA } \\
\end{array}$ & $\begin{array}{l}65 \text { years } \\
(40-82) \\
29 \% \\
\text { NA } \\
\end{array}$ & $\begin{array}{l}68 \text { years } \\
(33-92) \\
41 \% \\
20 \% \\
\end{array}$ & $\begin{array}{l}67 \text { years } \\
(39-85) \\
37 \% \\
\text { NA } \\
\end{array}$ \\
\hline $\begin{array}{l}\text { Inclusion/ } \\
\text { exclusion criteria }\end{array}$ & $\begin{array}{l}\text { Adequate organ } \\
\text { function for } \\
\text { docetaxel }\end{array}$ & $\begin{array}{l}\text { fit for chemotherapy } \\
\text { with no clinically } \\
\text { significant } \\
\text { cardiovascular history }\end{array}$ & & $\begin{array}{l}\text { significant } \\
\text { cardiovascular } \\
\text { comorbidity }\end{array}$ \\
\hline $\begin{array}{l}\text { Impact on } \\
\text { survival /age }\end{array}$ & $\begin{array}{l}\text { Improved OS } \\
\text { independent of } \\
\text { age, in high volume } \\
\text { group }\end{array}$ & $\begin{array}{l}\text { Improved OS } \\
\text { Underpowered for } \\
\text { older patients group }\end{array}$ & $\begin{array}{l}\text { Improved OS } \\
\text { Trend in OS impact in } \\
\text { older patients but } \\
\text { underpowered for } \\
\text { older patients group }\end{array}$ & $\begin{array}{l}\text { Improved OS } \\
\text { Underpowered for } \\
\text { older patients group }\end{array}$ \\
\hline $\begin{array}{l}\text { Age-stratified } \\
\text { efficacy outcomes } \\
\text { impact }\end{array}$ & Yes & Yes & Yes & Yes \\
\hline $\begin{array}{l}\text { Impact on pain } \\
\text { progression/age }\end{array}$ & $\begin{array}{l}\text { Delayed time to } \\
\text { clinical progression } \\
\text { in overall and high } \\
\text { volume population } \\
\text { (impact of } \\
\text { age unknown) } \\
\end{array}$ & NA & $\begin{array}{l}\text { Delayed time to pain } \\
\text { progression } \\
\text { (impact of } \\
\text { age unknown) }\end{array}$ & NA \\
\hline Impact QoL/Age & $\begin{array}{l}\text { decreased QOL at } 3 \\
\text { months but nearly } \\
\text { baseline levels by } \\
12 \text { months }\end{array}$ & NA & $\begin{array}{l}\text { Improved HRQOL } \\
\text { (impact of } \\
\text { age unknown) }\end{array}$ & NA \\
\hline Complications & $\begin{array}{l}\text { Neutropenic fever } \\
(6 \%)\end{array}$ & $\begin{array}{l}\text { Neutropenic fever } \\
(15 \%)\end{array}$ & HTA, cardiovascular & HTA, cardiovascular \\
\hline $\begin{array}{l}\text { Reported age- } \\
\text { stratified toxicity }\end{array}$ & No & No & No & Yes \\
\hline
\end{tabular}


Table 5. Estimated cancer incidence, mortality and prevalence worldwide in 2018-2040

\begin{tabular}{|c|c|c|c|c|c|c|c|c|c|}
\hline \multicolumn{10}{|c|}{ Incidence (new cases) } \\
\hline & 2018 & 2040 & Demo- & \multicolumn{2}{|c|}{2018} & \multicolumn{2}{|c|}{2040} & \multicolumn{2}{|c|}{ Demographic change } \\
\hline & All ages & All ages & All ages & Age $<70$ & Age $\geq 70$ & Age $<70$ & Age $\geq 70$ & Age $<70$ & Age $\geq 70$ \\
\hline World & $1,276,106$ & $2,293,818$ & $\begin{array}{c}1,017,712 \\
(+79.8 \%)\end{array}$ & 650,367 & 625,739 & 963,398 & $1,330,420$ & $\begin{array}{c}313,031 \\
(+48.1 \%)\end{array}$ & $\begin{array}{c}704,681 \\
(+112.6 \%)\end{array}$ \\
\hline $\begin{array}{l}\text { Inter-tropical } \\
\text { countries* }\end{array}$ & 317,831 & 656,049 & 338,218 & 142,175 & 152,887 & 302,785 & 358,777 & 160,610 & 205,890 \\
\hline $\begin{array}{l}\text { North America } \\
\text { \& Europe** }\end{array}$ & 585,901 & 778,661 & 192,760 & 322,806 & 263,095 & 337,783 & 440,978 & 14,977 & 177,783 \\
\hline \multicolumn{10}{|c|}{ Mortality (cancer deaths) } \\
\hline World & 358,989 & 737,994 & $\begin{array}{c}379,005 \\
(+105.6 \%)\end{array}$ & 78,844 & 284,145 & $1,129,974$ & 625,020 & $\begin{array}{c}38,130 \\
(+50.9 \%)\end{array}$ & $\begin{array}{l}340,875 \\
(+120 \%)\end{array}$ \\
\hline $\begin{array}{l}\text { Inter-tropical } \\
\text { countries* }\end{array}$ & 126,558 & 276,751 & 150,193 & 33,520 & 93,038 & 62,195 & 218,565 & 28,675 & 125,527 \\
\hline $\begin{array}{l}\text { North America } \\
\& \text { Europe** }\end{array}$ & 106,317 & 191,219 & 84,902 & 15,754 & 90,563 & 16,822 & 174,396 & 1,068 & 83,833 \\
\hline
\end{tabular}

Modified from ${ }^{3}$ : International Agency for Research on Cancer (IARC). Globocan 2018: estimated cancer incidence, mortality and prevalence worldwide in 2018. On line analysis: prediction (Cancer tomorrow). http://globocan.iarc.fr/Pages/burden sel.aspx

*Inter-tropical countries were defined according to IARC regions: Eastern Africa, Middle Africa, Southern Africa, Western Africa, Caribbean, Central America, South-Eastern Asia, South-Central Asia, Melanesia, Micronesia, and Polynesia. It also includes South America except Argentina, Chile and Uruguay.

** Europe, except Central and Eastern Europe. 